\title{
IMPACTO DE LAS VIVIENDAS DE USO TURÍSTICO EN ESPAÑA EN EL CONTEXTO PRE-COVID19: ESTUDIO DE CASOS MADRID E ISLAS BALEARES
}

\author{
Ana Medina López* \\ Universidad Rey Juan Carlos. Madrid \\ https://orcid.org/0000-0003-1956-1839 \\ Belén Fernández de Alarcón Roca** \\ Universidad Rey Juan Carlos. Madrid \\ https://orcid.org/0000-0003-1294-9566
}

\section{RESUMEN}

La industria turística se suma a la era digital incrementando la oferta de viviendas de uso turístico. El análisis de las externalidades negativas asociadas a este fenómeno vertebra este trabajo en cinco claves. Se sintetiza la normativa en dos destinos representativos: Baleares y Madrid. Se presenta una cuantificación de impactos económicos a nivel nacional, con la Tabla Input-Output de España 2015, constatando que un cambio de patrón de comportamiento del turista, asociado a los hábitos en viviendas vacacionales, genera impactos de diversa índole desde la óptica de la contabilidad nacional.

Palabras clave: turismo; viviendas de uso turístico; externalidades; Madrid y Baleares; análisis input-output.

Measuring the impact of home sharing use in Spain in the pre-covid19 context: Madrid and the Balearic Islands case study

Fecha de recepción: 2 de enero de 2020

Fecha de aceptación: 13 de mayo de 2020

* Departamento de Economía Financiera y Contabilidad II e Idioma Moderno. Universidad Rey Juan Carlos. Paseo de los Artilleros 38. 28032 Vicálvaro MADRID (España). E-mail: ana.medina@urjc.es

Esta autora agradece la financiación recibida del proyecto: ECO2016-75204-P (AEI/FEDER, UE). Este proyecto (ECO2016-75204-P) está financiado por el Ministerio de Economía y Competitividad y por el Fondo Europeo de Desarrollo Regional FEDER.

** Departamento de Humanidades. Camino del Molino s/n. 28943 Fuenlabrada MADRID (España). E-mail: belen.fernandezdealarcon@urjc.es 


\begin{abstract}
The tourism industry joins the digital era driving to an increase in the offer of home sharing for tourist use. The analysis of the negative externalities associated with this phenomenon supports this work in five keys. It synthesizes the regulations in two representative destinations: Balearic Islands and Madrid. Presents a quantification of economic impacts at national level, with Table Input-Output of Spain 2015, noting that a change of behavior pattern tourists associated with habits in housing for tourist, generates impacts of various signs from the perspective of national accounting.
\end{abstract}

Keywords: tourism; home sharing; externalities; Madrid and the Balearic Islands; inputoutput analysis.

\title{
1. INTRODUCCIÓN
}

La irrupción de plataformas digitales en la industria turística, en inglés denominadas Peer to Peer (P2P), que actúan como punto de encuentro entre propietarios particulares y turistas, oferta y demanda, ha supuesto un efecto distorsionador en el tradicional equilibrio existente en este mercado. Lejos de evolucionar hacia modelos de gestión de la oferta y la demanda con criterios de crecimiento sostenible, el sector hotelero viene observando, desde hace más de una década, cómo gran parte de su público objetivo se decanta por la contratación del alojamiento a través de las mencionadas plataformas digitales. Ante esta nueva realidad, se pone en evidencia una deriva hacia el aumento en la afluencia masiva de turistas, sin que este hecho lleve aparejada una contribución a la economía, un fomento del empleo y un impacto controlado sobre el medioambiente y los entornos de acogida.

La evolución del sector turístico mundial la resume el Panorama Internacional del turismo 2019, Zurab Pololikashvill, Secretario General de la OMT (UNWTO), afirma que "la digitalización, la innovación, una mayor accesibilidad y ciertos cambios sociales seguirá moldeando el sector, y tanto los destinos como las empresas tendrán que adaptarse para seguir siendo competitivos, a la vez que hacen que el turismo contribuya a alcanzar los Objetivos de Desarrollo Sostenible (en adelante ODS) y a construir un futuro mejor para todos". Por lo tanto, es fundamental aunar esfuerzos entre diversos agentes del sector turístico para conseguir un turismo más sostenible de acuerdo con los ODS que se configuran en la Agenda 2030.

Frente a un crecimiento exponencial de la oferta de viviendas de uso turístico se halla el sector hotelero, que percibe un trato asimétrico por parte de la regulación vigente y que tiene el reto de asumir una situación sobrevenida y radicalmente nueva. Resulta interesante analizar el extremo hasta el que la regulación de esta actividad se ajusta a la nueva realidad. Las plataformas digitales constituyen un nuevo modelo de negocio que no existía antes y que se ha expandido de forma vertiginosa por los destinos turísticos de todo el mundo. España posee un gran potencial turístico y, es de esperar, que no estén dispuestos a retirarse de este mercado clave por el atractivo que supone su volumen de turistas.

Ante este escenario, en palabras de Planas, M. (2020) "La existencia de múltiples plataformas de alquiler turístico ha empujado a las distintas comunidades autónomas a regular 
esta actividad, frente a la problemática que puede nacer de la misma. Consecuentemente, cada comunidad autónoma ha desarrollado unos requisitos y obligaciones distintos".

Se plantea como eje de la presente investigación el análisis de las externalidades generadas por las viviendas de uso turístico en dos destinos representativos del turismo en España: Madrid, por aglutinar los rasgos del turismo urbano, cultural y de negocios y Baleares en su vertiente de destino turístico de Sol y Playa. Este análisis constituye el punto de partida de un análisis de un marco jurídico que garantice el equilibrio en el sector y un posterior análisis cuantitativo de impacto económico. Así, en esta investigación se plantean analizar los siguientes objetivos:

\subsection{Objetivos}

En este trabajo de investigación se persigue analizar y verificar las externalidades que han generado las plataformas digitales, fenómeno de aparición y expansión desde principios del siglo XXI, en el mercado turístico español.

Se pretende sintetizar las normas reguladoras de las viviendas de uso turístico en un destino representativo de "Sol y Playa" como son las Islas Baleares. Seguidamente se persigue realizar un análisis similar en otro destino turístico de índole "urbana, cultural y de negocios" como lo es Madrid.

Para medir el impacto del fenómeno estudiado, se aporta una medición en términos agregados, desde una perspectiva macroeconómica de cuantificación de impactos económicos, con el fin de identificarlos efectos económicos, sobre los distintos sectores de actividad vinculados al turismo, resultantes del cambio de hábitos en la contratación de alojamientos turísticos.

\subsection{Estructura del análisis}

Para conseguir estos objetivos, el presente trabajo se ha estructurado de la siguiente manera: se realiza continuación una revisión de la literatura más reciente sobre este tema, después se profundiza en la situación actual derivada del surgimiento de la contratación de viviendas de uso turístico a través de plataformas digitales; seguidamente, se plantea un análisis articulado en cinco claves: económica, social, laboral, patrimonial y medioambiental, también se presenta un análisis de la situación actual en materia de regulación y normativa aplicable a los apartamento y a las viviendas de uso turístico tomando los dos casos concretos, Madrid y Baleares, como destinos representativos de dos tipologías de turismo. Una vez dimensionado el problema y analizada la regulación, se propone la metodología de multiplicadores lineales de (Leontief, 1936)para cuantificar los efectos de las externalidades previamente expuestas en el conjunto de la economía española; y para finalizar, se concluye extrayendo de todo lo anterior una serie de recomendaciones.

\subsection{Estado de la cuestión}

Han sido numerosos los autores que han profundizado sobre esta temática. Realizando una revisión de los más notables en relación con el tema que nos ocupa destacan, cronológicamente, entre 2016 y 2019, los trabajos que se comentan a continuación. 
-Del Busto, Ceballos Martín y Pérez Guerra (2019) aportan, mediante su investigación en la Comunidad de Madrid, que la legislación de alojamiento turístico en España, bajo la modalidad de apartamentos turísticos y viviendas de uso turístico, o similares denominaciones, presenta un importante nivel de dispersión y un alto grado de heterogeneidad. Así mismo, se advierte de que la jurisprudencia refleja amplias potestades de las Comunidades Autónomas para establecer disposiciones relativas a las diferentes modalidades de alojamiento, su ejercicio no es ilimitado. Y, concluyen en que las sentencias estudiadas son un precedente importante en la medida en que establecen límites concretos a la regulación en una actividad como la turística, donde se observa una clara tendencia al intervencionismo público, que, en ciertos casos, excede los marcos establecidos por la normativa comunitaria. Destacando, por su trascendencia, la Sentencia 291/2016, originada en el recurso interpuesto por la Comisión Nacional de los Mercados y la Competencia (CNMC) en el que se solicita se declare la nulidad de la norma contenida en artículo 17.3 del Decreto $79 / 2014$, por la que las viviendas de uso turístico no podrán ofrecerse por un período inferior a cinco días. Ello así, en tanto, es contrario a la competencia efectiva en los mercados que garantiza el art. 38 de la Constitución Española.

-Franch Fluxà (2019) analiza los aspectos más relevantes de la legislación de las Islas Baleares sobre las viviendas de uso turístico teniendo en cuenta que algunas de las medidas que ha aprobado el Parlament, durante la última legislatura, obedecen a una tendencia generalizada de restringir las estancias en viviendas. Teniendo en cuenta estudios y resoluciones que, si bien se han producido respecto a la normativa de otras CCAA, poseen relevancia para el diseño de la legislación balear completada con la aprobación de la Ley 6/2017 y el Decreto ley 3/2017. Dicha reforma se ha acompañado de una moratoria anual de las nuevas altas hasta la aprobación de los Planes de Intervención de Ámbitos Turísticos por los cuatro Consejos Insulars de las Baleares. Entre los principales objetivos de la reforma de la normativa balear sobre las estancias en viviendas el Parlament Balear hace, especial hincapié, en sus debates y en el expositivo de la Ley 6/2017 a la necesidad de proteger el medio ambiente, el uso sostenible de infraestructuras y recursos o la protección de los consumidores y usuarios.

- Zaar y Pontes da Fonseca (2019) describe un escenario en el que se observa especulación inmobiliaria y la mercantilización del espacio público con implicaciones sobre la relación entre residentes, turistas y agentes inmobiliarios/turísticos. Eligen el barrio barcelonés de La Barceloneta, dónde la demanda de los visitantes discrepa de las necesidades de los residentes y donde las actividades turísticas afectan la vida cotidiana de sus ciudadanos. Evalúan los impactos socio territoriales que causan un mayor nivel de rechazo vecinal y que han sido motivo de reivindicaciones y protestas que exigen la reglamentación de las viviendas de uso turístico (VUT) y del uso del espacio público, lo que se ha conseguido, aunque parcialmente según opinión de los autores, a través de la aprobación del PEUAT.

-Herrero Suárez (2017) argumenta que el enorme éxito experimentado por las plataformas de consumo colaborativo en los últimos años tiene un exponente claro en el sector del alojamiento turístico. A través de ellas, y como las operadas por la empresa estadounidense Airbnb se ha abierto un auténtico mercado en el que particulares, y, cada vez más profesionales ceden el uso de sus viviendas (enteras o por habitaciones) a terceros a cambio de una prestación económica con carácter puntual o esporádico. Para evitar la inseguridad jurídica que conlleva la situación de alegalidad o paralegalidad que plantean estos modelos, es 
conveniente dotar a estos nuevos mercados globales y virales de un marco adecuado, que pueda encontrar un punto de equilibrio entre la autorregulación por los operadores privados y los excesos regulatorios. También, manifiesta que no debería partir de un principio general prohibitivo ni restrictivo, al contrario, debería tratar de fomentar estas actividades, intentando mitigar sus eventuales efectos negativos. Siendo lo más efectivo, de forma paralela a lo que se ha hecho en otros ordenamientos, el interés directo de las plataformas y su cooperación o colaboración con las autoridades públicas, por ejemplo, implicándolas en la recaudación de tasas turísticas, o en el control del cumplimiento de los requisitos.

- Román Marquez (2018) señala que si bien el reglamento andaluz sobre viviendas particulares de uso turístico se mantiene dentro de los cauces marcados por sus antecesores en otras Comunidades Autónomas, destaca la ausencia de algunos requisitos para la comercialización de la vivienda, como la póliza de seguro frente a daños corporales o materiales que puedan sufrir los usuarios durante su estancia, algunos elementos de protección frente a incendios - extintores o mantas ignífugas - o el acceso wifi a Internet. Subraya este autor que también se echa en falta, como ocurre en resto de Comunidades Autónomas, la existencia de un mecanismo jurídico que concilie definitivamente las exigencias del planeamiento urbanístico con la naturaleza turística de estas viviendas. Indica que la doctrina ha puesto de manifiesto la conveniencia de extender la responsabilidad por la comercialización de viviendas clandestinas a los canales de intermediación turística, de forma que los sujetos susceptibles de ser sancionados por esta conducta no sean únicamente sus propietarios, sino también los canales que comercialicen viviendas no adaptadas a las exigencias del Decreto 28/2016. Remite a este respecto a las orientaciones que brinda la Agenda europea para la economía colaborativa.

-Velasco Kars (2016) asevera que el alquiler de las denominadas "viviendas turísticas" ha proliferado desde la aparición de plataformas de economía colaborativa como Airbnb o Homeaway, entre otros. Esta solución, trae consigo, una atractiva rentabilidad de entre un $5 \%$ y un $10 \%$ para los propietarios que pongan sus viviendas a disposición de los turistas.

-Miralles Marugán y Villar Lama (2016) confirman que en los últimos años se viene presenciando un continuo descontento de los agentes turísticos ante la aparición y falta de regulación de empresas de economía colaborativa en el sector. En su estudio se investigó, de manera cualitativa, el conflicto existente entre las plataformas Peer to Peer (P2P) y la oferta reglada en el ámbito del alojamiento en España. En este trabajo se ha analizado la normativa internacional y se ha implementado una metodología de análisis del discurso mediante un software específico (Atlas.ti). Los autores defienden que el sector hotelero busca el descenso de la actividad de las empresas de economía colaborativa al exigir su regulación, y que los usuarios $\mathrm{P} 2 \mathrm{P}$ seguirán alojándose en estas viviendas mientras crean que aportan un beneficio económico y/o social en el destino. Asimismo, existen discrepancias sobre cuál es el perfil del cliente de esta tipología de alojamiento.

- Guillén Navarro (2015) publicó un artículo en la Revista Aragonesa de Administración Pública, uno de los primeros análisis sobre la incidencia de las viviendas de uso turístico en el panorama normativo español, confirmando el auge de este tipo de alojamientos ofertados a través de internet, y cómo la aplicación de home sharing ha revolucionado el concepto de alojamiento vacacional. En la conclusión lanza el mensaje de la importancia de una regulación en este tipo de actividades turísticas, debido a los diversos problemas secundarios que conlleva: competencia desleal, economía sumergida, gentrificación, y otros. 


\section{SITUACIÓN ACTUAL DERIVADA DE LA CONTRATACIÓN DE VIVIENDAS DE USO TURÍSTICO A TRAVÉS DE PLATAFORMAS DIGITALES}

Es diversa la tipología de alojamientos con fines turísticos: hoteles, apartamentos turísticos y viviendas de uso turístico. Los tres tipos de alojamientos son competidores directos sin embargo la normativa no es igual para todos, y es en este punto donde radica el origen del desequilibrio que se ha traducido en diversas externalidades.

Muchos empresarios hoteleros piensan que las viviendas de uso turístico se están desmarcando de la legalidad, y este hecho no solo tiene problemas de seguridad en destino, sino también que se va adquiriendo el denominado fenómeno de gentrificación o pérdida de identidad en los barrios de las ciudades y otro tipo de problemas subyacentes. Se percibe cierta incomodidad entre empresarios hoteleros que se refieren a la ventaja que tienen las viviendas de uso turístico sin barreras económicas o jurídicas a la hora de llevar a cabo su actividad, permitiendo a los propietarios de estas viviendas librarse de pagar muchos impuestos, surge la duda de si son prácticas que están al margen de la legalidad o, como algunas voces sugieren, de economía sumergida.

Los propietarios de viviendas de uso turístico para defenderse alegan que el crecimiento se debe al crecimiento del turismo en la ciudad, y para facilitar la infraestructura (porque muchas licencias para la construcción de hoteles van muy lentas), así ellos se ofrecen para dar respuesta a la demanda turística.

El cliente de hotel, a grandes rasgos, se caracteriza por realizar estancias cortas, ir en pareja, a veces en familia, con un nivel adquisitivo superior. Los apartamentos turísticos se ajustan a perfiles de turistas que realizan estancias más largas y están más preparados para familias o grupos de amigos, y las viviendas de uso turístico, en este momento, engloban todo tipo de perfiles, muchas veces se eligen por su ubicación en cascos históricos, en el caso de turismo urbano, o cerca de las playas, cuando se realiza turismo de Sol y Playa.

\subsection{Análisis en cinco claves}

Para dimensionar el alcance de las externalidades vamos a profundizar en cinco claves siguiendo el enfoque de las fuerzas motrices o drivers del estudio realizado por Gottlieb Duttweiler Institute en el año 2006. En este apartado analizamos la económica, social, laboral, patrimonial y medioambiental.

\subsection{Clave económica}

El Banco de España en 2018 constató una elevación media anual de los ingresos por turismo de la balanza de pagos de un 5\% en el período 1993-2018, tras la revisión extraordinaria 'Benchmark' de las estadísticas macroeconómicas implementada en septiembre de 2019. Desde el punto de vista de la competitividad del sector, es responsable de la generación del 12,8\% del empleo en España en 2019 según datos de la Encuesta de Población activa publicada por el Instituto de Nacional de Estadística, (en adelante EPA e INE, respectivamente). En cuanto a su aportación al PIB, la Cuenta Satélite del Turismo elaborada por el INE, en 2019 lo sitúa en el 12.3\%. Datos que han configurado al turismo 
como el primer sector productivo nacional. Al haber sido también una fuente importante de entrada de divisas y, en general, un contribuyente neto de recursos, ha permitido compensar parte del desequilibrio comercial de la economía española. Además, esta actividad constituye un vehículo de integración regional y un catalizador de la colaboración pública y privada en el diseño y la gestión de las actividades relacionadas.

Para constatar la trayectoria del sector basta con observar la evolución de las pernoctaciones en hoteles desde abril de 1965, fecha desde la que se tiene registro en las estadísticas de Banco de España hasta mediados de 2019.

\section{Figura 1 \\ VIAJEROS ALOJADOS EN HOTELES}

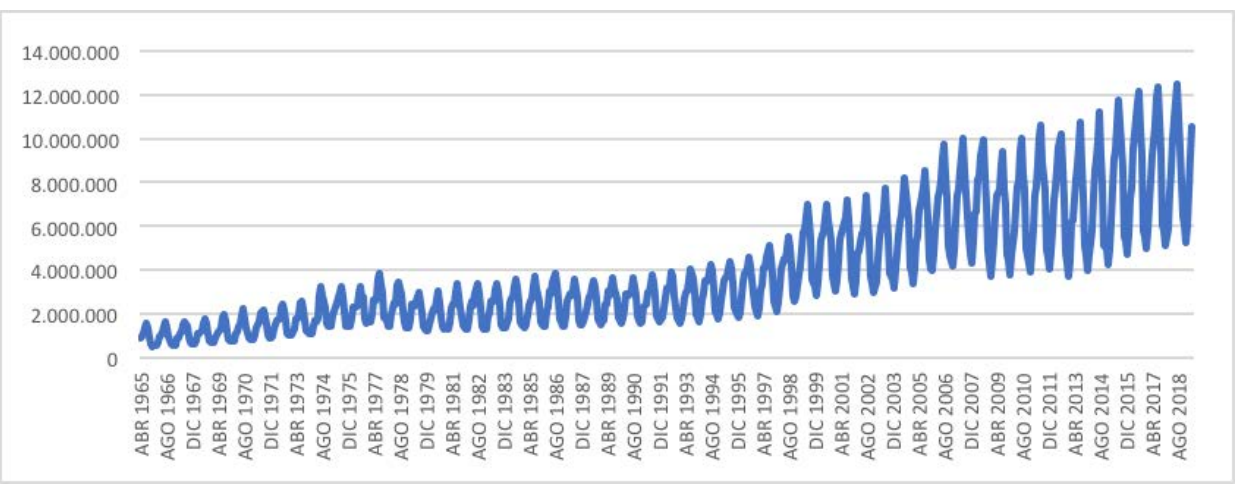

Fuente: Banco de España (serie de abril 1965 a enero 2019)

En clave económica, se aprecia la presencia de cierta polaridad, puesto que se comercializa desde hace unos años o bien un turismo de lujo o bien uno de prácticas muy ajustadas en gasto, por lo tanto, además del low-cost aplicado al turismo también aparece el lujo. Además, ante la ausencia de regulación en los primeros años de la crisis del periodo 2010-2016,se antepusieron objetivos como pudiera ser la obtención de ingresos extra por parte de las economías domésticas frente a otros fines más acordes con una planificación estratégica a largo plazo, que involucrara a todos los agentes que intervienen en la cadena de valor del producto turístico. Las plataformas de contratación P2P captaron clientes en esos años y posteriormente han seguido afianzando cuota de mercado, llegando incluso a abrir la puerta a nuevos perfiles de turistas.

\subsection{Clave social}

Cuando se interpreta el fenómeno en clave social cabe estudiar el perfil del viajero y tener en cuenta factores que han sido analizados por autores como Moutinho (1987) quién señala que el comportamiento del consumidor se orienta hacia la consecución de objetivos determinados al viajar, convirtiendo la identificación de las motivaciones turísticas en un elemento crucial para la comprensión y el análisis del comportamiento del turista y su 
decisión de compra. Las principales influencias en dicho comportamiento son el nivel cultural, la clase social y los grupos de referencia a los que pertenezcan. Estos aspectos se entrelazan en segunda instancia con: la personalidad del viajero, su trayectoria y aprendizaje previos, sus motivaciones, su percepción del destino y las actitudes frente al viaje. Si tenemos en cuenta estos factores y nos situamos en una realidad social que avanza al ritmo de la tecnología, entendemos que surgen nuevos hábitos, así como estructuras familiares características de sociedades avanzadas.

Por tanto, la situación es la siguiente: la prospectiva sobre llegada de turistas está en aumento, el perfil del viajero está cambiando debido al desarrollo de las tecnologías de la información y la comunicación, ya que conviven diferentes cohortes generacionales que van desde la generación platino (mayores de 55), los babyboomers, la generación X, la generación $\mathrm{Z}$ y la siguiente que está llegando, la generación $\mathrm{T}$, que son los últimos que no han tenido contacto alguno con el mundo analógico. Además, cada vez hay más demanda directa por parte del turista individual y cada vez viajan más personas solas o en pareja y menos familias. Al aumentar la esperanza de vida Sánchez García, V. (2013:37) señala que "en Europa se prevé que para el año 2020 el número de personas mayores de 65 años representará un $20 \%$ de la población. Este grupo dispondrá de más poder adquisitivo y tiempo libre, lo que supone un gran potencial en cuanto al mercado turístico, por su capacidad de consumo y por su capacidad de romper con la estacionalidad". La revolución tecnológica ha acercado a todas las generaciones a las plataformas digitales donde la información es más rápida y accesible. Es un hecho que la mayoría de las empresas hoteleras las utilizan como herramienta comercial, aunque probablemente no han conseguido aún el mismo recorrido que las plataformas digitales.

Si los turistas tienden a hacer uso de plataformas digitales en lugar de los canales de venta tradicionales, entendemos que la clave donde se manifiesta la competencia es en la tecnología del sector turístico, agravando a unos (sector hotelero) aumentando el valor y la comercialización de viviendas de uso privado, por días, semanas o quincenas. La oferta descontrolada de estas últimas, en clave social, está provocando cuatro tipos de externalidades: a) exceso de oferta, b) la convivencia vecinal se ve afectada por conductas disruptivas, c) proliferación de actividades turísticas y de ocio que generan un funcionamiento anómalo en los hábitos en el lugar de recepción, d) gentrificación turística, se trata de una de las externalidades de reciente aparición, asociada al turismo urbano. Se denomina así a la llegada masiva de turistas a un barrio, que representan una población flotante que fuerza la expulsión de parte de los residentes y comercios tradicionales, debido a la inflación que se produce en la zona.

Este proceso, además, genera especulación inmobiliaria en torno a los pisos turísticos, pues el alquiler en estos barrios puede reportar grandes rentabilidades, con lo que proliferan viviendas de uso turístico al margen de la legalidad. Este hecho es un factor que presiona al alza el precio de las viviendas tanto de compra como de alquiler. De forma colateral, este incremento descontrolado sobrepasa la capacidad de carga en destino pues no va acompañado de una planificación y desarrollo parejos en infraestructura y transporte.

\subsection{Clave laboral}

Analizar el fenómeno desde el punto de vista del mercado de trabajo implica necesariamente cuantificar los recursos humanos que trabajan en el sector turístico que repre- 
sentan alrededor del 13\% del empleo nacional según la EPA (2019) y adicionalmente, constituyen la piedra angular del mismo por varios motivos. La mayoría de los servicios que recibe el viajero dependen del contacto directo o indirecto con acciones en las que intervienen una amplia tipología de profesionales, sin ánimo de ser exhaustivos podemos pensar en: piloto de avión, capitán de barco, conductor de autobús, gestor/responsable comercial que atiende a los clientes, monitor/animador, encargado de lavandería, cocineros, gobernanta, jefe de sala, agente de viajes, diversos responsables de animación, administrativo, azafata, camarero, planchador, director, gerente, limpiador, gestor de venta, experto en marketing, recepcionista, ayudante en cualquiera de los ámbitos, mantenimiento, conserje, portero u ordenanza.

La enumeración expuesta deja claro que se trata de un sector intensivo en mano de obra y trasluce varios intangibles ya que tratan de relaciones interpersonales, el trato con el cliente, con mayor o menor profesionalización y su experiencia. Este hecho pone de manifiesto la relevancia que ha de tener en España el número de empleos ligados al sector turístico, dado su peso del $12.3 \%$ en el PIB, además de lo deseable que ha de ser su formación y una legislación acorde con el dinamismo y la estacionalidad que caracterizan el sector.

Encontramos cuatro factores para caracterizar las condiciones a las que se enfrentan los trabajadores vinculados al sector turístico: la primera es la irregular distribución de la demanda en el tiempo (ya sea dentro del mes, de la semana o del día), la segunda es la heterogeneidad de subsectores de actividad vinculados al turismo, la tercera proviene del hecho de ser actividades intensivas en mano de obra y la cuarta reside en la atomización del sector (en pymes de menos de 10 empleados y autónomos).

Por otro lado, es un sector que se enfrenta a una demanda irregular, estacional e imprevisible. Para añadir más volatilidad y fruto del dinamismo digital, están surgiendo nuevos perfiles profesionales que obligan a los recursos humanos a recibir cursos de formación, que si bien aportan valor añadido también requieren un gran esfuerzo inversor tanto en términos de tiempo como de tiempo de formación. Se trata de perfiles con un nivel de cualificación alto tales como gestores estratégicos de ventas; gestores de información, canales, contenidos y marketing; product manager, ingenieros y gestores de procesos; gestores de redes sociales; desarrolladores de marcas; gestor de innovación; planificador de destinos turísticos y gestor cultural.

Sin embargo, estudios recientes como el estudio sobre el empleo en el sector turístico español elaborado por Exceltur (2018:21) concluyen que las estadísticas globales sobre salarios y niveles de cualificación del sector se sitúan por debajo de la media respecto al resto de otros grandes sectores de la economía española, no se percibe lo suficiente el papel de la industria turística en la generación de puestos de trabajo para la gestión ni la aparición de nuevos perfiles profesionales de alto valor añadido y no se valora el efecto sobre la creación de empleo en otros sectores profesionales que trabajan para el turismo.

Una vez caracterizado un mercado laboral, específico del sector turístico, avanzamos un paso más para profundizar en el tema que nos ocupa, es decir en el impacto que está generando sobre el empleo turístico el uso extensivo de los servicios de alojamiento en viviendas de alquiler turístico. Hemos considerado este impacto como una externalidad negativa ya que a pesar de que las cifras que informan sobre el volumen de llegadas de turistas a territorio español arrojan saldos positivos y crecientes, dichos aumentos parece 
ser que no se traducen en un efecto multiplicador en términos de renta, empleo, valor añadido, calidad de vida, ni con impacto social y ambiental positivo en la economía española.

El empleo directo y el inducido generado en España por cada vivienda de alquiler turístico son muy inferiores a lo que hoy crea la industria del alojamiento regulado, y principalmente, hotelero.

El estudio sobre el empleo en el sector turístico español elaborado por Exceltur (2018) subraya que el marco jurídico laboral condiciona la flexibilidad y la seguridad de los trabajadores vinculados al sector turístico, por lo que la reforma laboral de 2012 fue clave ya que: las empresas requieren flexibilidad interna a la hora de contratar, los contratos a tiempo parcial permiten que adaptarse a los erráticos horarios del turista y el contrato para formación y aprendizaje refuerza un modelo dual que aporta ventajas a trabajador y empresario.

\subsection{Clave patrimonial}

Al hablar de patrimonio y turismo es necesario conocer los agentes implicados en el turismo cultural. Se distingue la demanda, la oferta, los agentes turísticos y el territorio. La demanda es el conjunto de individuos que consumen turismo cultural. Por una parte, se encuentran todos aquellos que acuden a estos destinos como actividad educativa de forma voluntaria o no, de forma individual, o en grupo, motivados siempre por temas culturales. En este contexto nos encontramos con una población segmentada que perciben diferentes imágenes del destino en función de su perfil demográfico, económico y sociocultural.

Entendemos por la oferta como el conjunto de recursos (productos y servicios, recursos naturales, organizaciones, alojamientos, instalaciones, e infraestructuras),que se encuentran a disposición de los visitantes para su consumo en destino. Todo ello formará "la experiencia turística". Así pues, los destinos son territorios con rasgos propios (paisajísticos, medioambientales, culturales y sociales) con un conjunto de infraestructuras, servicios y equipamientos que en términos de mercado se posicionan en la mente de los consumidores.

Como externalidades fruto de la masificación del turismo puede ocurrir que ciertas actividades recreativas degraden los valores históricos y lugares emblemáticos, y que se desvirtúen las costumbres y tradiciones perdiendo la autenticidad y la fidelidad a los vínculos históricos.

Los agentes turísticos son definidos por la OMT (1998) como organizaciones públicas y privadas que participan en la actividad turística, generalmente en calidad de intermediarios entre el consumidor final y el producto turístico, convirtiendo los recursos turísticos en productos para satisfacer las motivaciones de los turistas. Se consideran fundamentales, por su labor de comunicar a la demanda la imagen del destino mediante actividades de marketing. En el artículo que estamos analizando, juega un importante papel como agente turístico las plataformas online de venta de viviendas de uso turístico. El territorio, es un actor que ha tenido diversas interpretaciones, según la intención de cada autor. Seguimos la definición de la OMT (1998) que lo considera como un espacio geográfico, definido como base física donde se produce la conjunción entre la oferta y la demanda turística y se encuentra la población residente.

Como observamos son varios los agentes que conforman la imagen positiva o negativa de un destino turístico y por ende de su valor patrimonial. En España la política o conjunto 
de acciones implicados en la conservación, restauración y planificación de bienes culturales que incidan en el turismo cultural tienen un complejo sistema. Primordialmente, son las Comunidades Autónomas, seguidamente el Gobierno Central que tiene un papel muy variable según el ámbito, y finalmente asistimos a un desigual nivel local (puesto que no todos los Ayuntamientos conceden la misma importancia a la cultura en una determinada localidad).

En cuanto a la interrelación del turismo y el patrimonio no hay que olvidar que toda actividad turística genera consecuencias tanto económicas como sociales para los lugares de destino. Para analizar esta cuestión seguimos a (González-Varas, 2015: 88) "el turismo estimula la inversión directa, tanto en la propia industria turística como, por su naturaleza multisectorial, en los sectores auxiliares próximos, inmobiliario y comercio, incide en el desarrollo de las infraestructuras, equipamientos y servicios y por ello reactiva las inversiones públicas". Se revitaliza el interés de los habitantes por la cultura expresado a través de las costumbres, artesanías, folklore, fiestas, gastronomía, así como el conocimiento del patrimonio monumental que puede tener una ciudad. Se contribuye a atenuar o romper la estacionalidad en destinos, además puede suponer un recurso de posibilidad de desarrollo local en determinadas comunidades rurales ante la nueva demanda turística. Por el contrario, un turismo masivo e incontrolado genera consecuencias negativas para el patrimonio cultural.

Hay destinos turísticos que se han visto obligados a restringir el acceso en sus instalaciones, como es el caso de las Cuevas de Altamira en Santillana del Mar en España, donde se tuvo que cerrar la cueva, construyéndose una neocueva, y en la actualidad, tan sólo unos pocos afortunados "madrugadores" son los que pueden acceder a la visita de la cueva original. El motivo principal de la degradación es la contaminación antrópica, o del ser humano, que deteriora la piedra. También algunas ciudades como Venecia o Dubrovnik han limitado el acceso de cruceros en determinados puertos. Afirma González-Varas (2015:92) "la actividad turística masiva y descontrolada o la superación de los límites de carga estipulada para un destino turístico-cultural desatan una serie de efectos nocivos entre los que destacan el pillaje de sitios históricos". Un ejemplo actualizado lo tenemos en los grafitis que se realizaron en la Catedral de Santiago de Compostela en 2019. Otros efectos considerados son la contaminación acústica, producto de la congestión del tráfico en destinos masificados o saturados, todo ello se debe al desarrollo de un turismo urbano incontrolado. Este hecho puede producir deterioro estético en el paisaje urbano, y también el rechazo por parte de las comunidades visitadas cuando no se respetan los sitios sagrados o las costumbres del lugar sintiendo una invasión en su espacio vital.

La mercantilización extrema de costumbres y tradiciones locales puede llegar a despojarlas de su verdadero significado, y fomentar el proceso de desculturización, GonzálezVaras (2015:92), convirtiendo la cultura local en un mero objeto de consumo. Asimismo, se tiende en muchas zonas a perder la identidad con determinadas prácticas rituales o manifestaciones étnico-culturales, llegando a su banalización. En realidad, lo que se produce es una aculturización de la población receptora, también se puede producir en ciertos destinos, un mercado negro de antigüedades o bienes del Patrimonio artístico.

Querol, M. (2010), afirma que el consumo masivo de historia puede significar la congestión de los centros históricos, así como la transformación social de los barrios y de la tradición, y que existe el riesgo de crear o inventar elementos tradicionales que poco tiene que ver con la realidad. Centrándonos en la masificación del turismo en las playas, 
se origina un sentimiento de decepción o frustración por parte de los turistas cuando no se responde a sus expectativas; es decir, cuando lo que esperan no se corresponde con la realidad. Un claro ejemplo de desvirtualización del paisaje se encuentra en la Playa de Palma, Magalluf, entre otras zonas costeras, donde los hoteleros intentan llevar a cabo una campaña en contra del turismo de "botellón" porque se deteriora la limpieza de las aguas de Baleares, además de ser nocivo para la imagen estética de la isla y suponiendo una merma en la calidad de su turismo.

Para finalizar el debate sobre la clave patrimonial, corroboramos lo que indica Querol (2010:487) respecto a las grandes desigualdades existentes en las regiones en cuanto a la explotación de los bienes culturales. Mientras algunos, como los grandes museos o sitios de Patrimonio Mundial reciben numerosas visitas y corren muchos riesgos de "sobreexplotación", otros, apenas se visitan, y languidecen en soledad y abandono.

\subsection{Clave medioambiental}

La consideración de la existencia de estrechas relaciones entre "cultura, patrimonio y sostenibilidad" es reciente, de finales de los años noventa. La sostenibilidad es uno de los conceptos más evocados en los últimos tiempos. Se entiende como un compromiso desde el presente hacia el futuro. En los medios de comunicación es frecuente escuchar noticias referentes al cambio climático y desarrollo sostenible. El primer documento referente a ello aparece en 1987 por la entonces Primera Ministra noruega Gro Harlem Brundtland. En este documento se define como sostenible "aquel desarrollo que satisface las necesidades del presente sin comprometer la capacidad de las generaciones futuras para satisfacer sus propias necesidades".

El descubrimiento más relevante de numerosos estudios aportados por científicos (biólogos, geólogos, climatólogos etc.) es la idea de que existe un límite natural y que los recursos naturales se están agotando. Por lo tanto, se hace necesario, preservar los existentes (playas y parajes de interés cultural). En 1995 la comisión Mundial de Cultura y desarrollo de las Naciones Unidas planteó la necesidad de alcanzar un compromiso entre cultura y desarrollo. Se definió Sostenibilidad Cultural entendiendo "la gestión del capital cultural como la cultura que hemos heredado de nuestros antepasados y antepasadas, y legaremos a próximas generaciones". A partir de entonces, han sido numerosos las publicaciones que interrelacionan turismo y sostenibilidad.

La ONU propone 17 Objetivos de Desarrollo Sostenible (ODS) para el año 2030. Dentro de estos objetivos se incluyen 169 metas, algunas relacionadas con la cultura y el turismo, destacan los siguientes objetivos.

En el objetivo 8, la meta 8 enuncia "Para 2030, elaborar y poner en práctica políticas encaminadas a promover un turismo sostenible que cree puestos de trabajo y promueva la cultura y los productos locales". Aquí se remarca la subordinación de la cultura al turismo.

En el objetivo 11. Lograr que las ciudades y los asentamientos humanos sean inclusivos seguros, y sostenibles, la meta 11 propone "redoblar los esfuerzos para proteger y salvaguardar el patrimonio cultural y natural del mundo".

En el objetivo 12.Se establece la meta 12.b, que indica que se deben de "elaborar y aplicar instrumentos que permitan seguir de cerca los efectos en el desarrollo sosteni- 
ble con miras a lograr un turismo sostenible que cree puestos de trabajo y promueva la cultura y los productos locales".

Una vez que se verifican estos objetivos definidos en la Cumbre Mundial de la ONU de 2015, para el Desarrollo Sostenible de la Agenda 2030, se hace necesario considerar una planificación y gestión adecuada a nivel internacional, nacional y autonómica con el fin de evitar catástrofes que serían nocivos para las futuras generaciones.

\section{REGULACIÓN EN LAS ISLAS BALEARES}

La regulación turística para la isla de Mallorca se puede encontrar en las siguientes Leyes y Reglamentos:

- Ley 8/2012, de 19 de julio del turismo de las Islas Baleares (BOIB No. 106, de 21 de julio de 2012).

- El Decreto 20/2015, de 17 de abril, de principios generales y directrices para la coordinación en turismo; de regulación de órganos consultivos, coordinación y cooperación del Gobierno de las Islas Baleares, y regulación y clasificación de empresas y establecimientos turísticos, emitido en desarrollo de la Ley 8/2012, de 19 de julio, de turismo de las Islas Baleares. (BOIB No. 56, 18 de abril de 2015).

- Ley 6/2017, de 31 de julio, de modificación de la Ley 8/2012, de 19 de julio, de Turismo de las Islas Baleares, relativa a la comercialización de estancias turísticas en propiedad residencial. (BOIB No. 93 de 31 de julio de 2017), también conocida como LTIB, Ley de Turismo Islas Baleares.

- Ley 6/2018, de 22 de junio, que modifica varias normas del ordenamiento jurídico en materia de turismo, función pública, presupuesto, personal, urbanismo, gestión farmacéutica, transporte, residuos y régimen local. (BOIB No. 78 del 26 de junio de 2018).

\subsection{Tipología Estancias Turísticas en Vivienda (ETV)}

Siguiendo la Ley 6/2017, se establecen las siguientes tipologías:

\subsubsection{Estancias Turísticas en Viviendas Unifamiliares (conocidas como ETV unifamiliares de 365 días)}

- Son aquellas viviendas ubicadas en un edificio que tenga una única vivienda, a saber:

- Las viviendas unifamiliares aisladas o chalets (compartan o no parcela con otros).

- Las viviendas unifamiliares entre medianeras únicas en la parcela.

- Las viviendas unifamiliares pareadas siempre que no compartan parcela.

- Las viviendas correspondientes a un edificio en el que haya una sola vivienda y uno o varios locales destinados a otros usos con entradas independientes (ejemplo: edificio en el que los bajos son local comercial y la planta superior, vivienda). Estas plazas se pueden alquilar durante todo el año, no caducan y se deben adquirir de la Bolsa de la Consejería de Turismo del Gobierno de las Islas Baleares. 


\subsubsection{Estancias Turísticas en Viviendas Plurifamiliares (conocidas como ETV plurifami- liares de 365 días)}

Se refieren a las viviendas ubicadas en edificios con dos o más viviendas que compartan accesos o elementos comunes, a saber:

- Las viviendas ubicadas en edificios de pisos en los que haya otras viviendas.

- Los edificios de viviendas adosadas (son un mismo edificio con varias viviendas que, además, comparten parcela).

- Las viviendas pareadas que comparten parcela (estaríamos ante un mismo edificio con dos viviendas que, además, comparten parcela). Estas plazas se pueden alquilar durante todo el año, caducan a los 5 años y se deben adquirir de la Bolsa de la Consejería de Turismo del Gobierno de las Islas Baleares.

\subsubsection{Estancias Turísticas en Viviendas de Residencias Principal (conocidas como ETV plurifamiliares y unifamiliares de 60 días)}

Estas plazas pueden ser comercializadas durante 60 días al año, caducan a los 5 años $\mathrm{y}$, en cualquier caso, debe ser la vivienda habitual y de empadronamiento de la persona propietaria. No permitiéndose arrendar durante los meses de julio y agosto correlativamente, solo uno de los dos.

\subsection{Exclusiones y restricciones al alquiler vacacional}

No se permitirá el arrendamiento de propiedad vacacional en las siguientes circunstancias:

- Cuando la vivienda esté o haya estado sometida a régimen de protección oficial o precio tasado.

- Si se hubiera impuesto una sanción firme por infracción grave o muy grave de la legalidad urbanística, mientras no se restituya dicha legalidad.

- Cuando lo prohíba la comunidad de propietarios, si la vivienda está sometida al régimen de propiedad horizontal.

- Cuando la comercialización de la misma no se haga en su totalidad. Está prohibido el alquiler por habitaciones.

- Cuando la estancia no sea de corta duración, es decir, cuando el período de alquiler es superior a un mes natural.

- Cuando se pueda acreditar de forma fehaciente que se ofrece de forma gratuita la posesión a un amigo o familiar.

- El número máximo de propiedades de una persona, grupo de propietarios o sociedad para alquilarse legalmente es de 3 propiedades o menos.

- Cuando la vivienda esté situada en suelo rústico protegido. No obstante, los PIAT (Planes de Intervención en Ámbitos Turísticos) o los PTI (Planes Territoriales Insu- 
lares) de cada isla pueden, de manera motivada, establecer otras previsiones con respecto al caso.

\subsection{Zonificación turística}

Las zonas aptas donde se podrá llevar a cabo la actividad turística serán las que se acordaron y delimitaron entre respectivos Plenos de los Consejos Insulares de Mallorca, Menorca, Ibiza, Formentera y el Ayuntamiento de Palma se declaren y, posteriormente, se recogen en los Planes de Intervención en Ámbitos Turísticos (PIAT) y Planes Territoriales Insulares (PTI).

Además, los Consejos Insulares, en el ámbito de sus competencias, podrán determinar no sólo las zonas aptas, sino también las tipologías permitidas, de tal forma que es posible que en una zona se permita un determinado tipo de ETV y en otra no. En este orden, en el art.5 de la Ley 6/2017, de 31 julio, de modificación de la Ley 8/2012, de 19 julio, del turismo de las Islas Baleares, relativa a la comercialización de estancias turísticas en viviendas, se incluye que «los PIAT y, si procede, los PTI (planes de intervención en ámbitos turísticos (PIAT) y, si procede, los planes territoriales insulares (PTI)) pueden determinar también el límite máximo por isla de plazas turísticas en alojamientos turísticos y el límite máximo de plazas en viviendas residenciales susceptibles de ser comercializadas turísticamente, en función de los recursos insulares existentes, las infraestructuras, las densidades de población y otros parámetros relevantes de su ámbito. En este supuesto, las bolsas de plazas se tienen que adaptar a esta cifra.»

Es importante señalar cómo se determinaron en función de las densidades turísticas máximas, aplicando las delimitaciones de zonas aptas aprobadas por el Consejo Insular de Mallorca y el Ayuntamiento de Palma, criterios de "Zonificación turística", distinguiéndose las de suelo rústico protegido (totalmente prohibido), y zonas turísticas con determinadas limitaciones

\subsection{Cantidad y coste de las plazas turísticas}

Las licencias de turismo se venden a través del Consorcio de la Bolsa de Alojamientos Turísticos (CBAT) en función de la capacidad de alojamiento de la propiedad (en base a su certificado de ocupación). En el momento que se publicó en el PIAT había 43.000 plazas disponibles y el precio variaría en función del tipo de vivienda y la modalidad elegida:

- Para una vivienda unifamiliar ETV365, el precio es de $3.500 €$ por plaza.

- Para una vivienda plurifamiliar ETV365, el precio es de $875 €$ por plaza.

- Para la modalidad de comercialización de la vivienda principal por un máximo de dos meses al año ETV60 el precio es de 291,67€ por plaza.

\subsection{Situación actualizada isla de Mallorca}

En Mallorca, la actual oferta de alquiler vacacional se puede ampliar en 20.000 plazas y un límite máximo de 10.000 plazas en hoteles y otros establecimientos de alojamiento turístico. Se ha informado públicamente que, a las dos semanas de que las plazas salieran a 
la venta, se presentaron 616 solicitudes, lo que significan 2.999 plazas. Casi el $80 \%$ fueron para apartamentos. El 14.1\% (67) de las solicitudes fueron para unifamiliares, representando 424 plazas y el $6.3 \%$ restante (32 solicitudes) fueron para residencias principales que serían alquiladas por un máximo de 60 días al año, lo que representa 189 plazas.

La Sesión Plenaria del Consejo de Mallorca, en sesión de 27 de julio de 2018, adoptó el acuerdo para aprobar definitivamente la delimitación provisional de áreas aptas para la comercialización de alquileres vacacionales en propiedades residenciales en Mallorca (excluyendo la capital Palma de Mallorca). Por primera vez, los alquileres vacacionales están legalmente permitidos en los apartamentos, aunque no en todas las áreas.

En algunas áreas que se consideran las más saturadas de turistas, solo se puede alquilar la residencia principal (donde el propietario está registrado como residente), por un máximo de 60 días por año, y solo durante julio y agosto.

Según este reglamento, en las zonas de la isla que han sido clasificadas como zonas turísticas maduras, las propiedades están limitadas a un máximo de 60 días de alquiler por año, con la mitad (30 días) solo en julio o agosto.

\subsection{Requisitos para solicitar licencia de estancia turística}

Para solicitar una licencia de alquiler vacacional en Mallorca, la propiedad debe cumplir con los siguientes requisitos mínimos establecidos en la Ley 6/2017, de 31 de julio, relativa a la comercialización de estancias turísticas en viviendas. Es interesante que se especifica tener al menos una antigüedad de 5 años. Durante este período, el uso de la casa debe haber sido residencial privado.

Esta es una exigencia específica de antigüedad que se requerirá a las viviendas de uso residencial que quieran presentar las declaraciones responsables para comercializar estancias turísticas, que será de cinco años durante los cuales, además, el uso tendrá que haber sido residencial privado. Ello, porque, como dice el mismo concepto, tienen que ser viviendas de uso residencial y, por lo tanto, tiene que haber una consolidación previa y real de este uso residencial antes de poder ser comercializada turísticamente. Se trata de evitar saturaciones, especulaciones urbanísticas y otros perjuicios al interés general.

Dicha exigencia es fruto de la modificación del artículo 50 de la Ley 8/2012, de 19 de julio, del turismo de las Islas Baleares hecha por la Ley 6/2017, de 31 de julio, relativa a la comercialización de estancias turísticas en viviendas:

Las viviendas residenciales respecto de las cuales se presente la declaración responsable con el fin de iniciar la actividad de comercialización de estancias turísticas deben tener la antigüedad mínima que se determine reglamentariamente, acreditable mediante la declaración de obra nueva o la licencia de primera ocupación, o mediante un certificado municipal emitido a este efecto. Durante este periodo el uso de la vivienda tiene que haber sido residencial privado. En defecto de reglamentación, la antigüedad mínima será de cinco años.

\subsection{Zonificación del alquiler turístico en Menorca}

El Consejo Insular de Menorca, el día 16 de julio del año 2018, prohibió el alquiler turístico en las siguientes zonas: 
1. Suelo rústico

2. En los núcleos urbanos tradicionales

3. En los ocho núcleos de población (Maó, Ciutadella, Ferreries, Es Mercadal, Es Migjorn Gran, Alaior, Es Castell y Sant Lluís)

4. En las urbanizaciones que no sean turísticas

Salvo, y como excepción, aquellos propietarios de viviendas en zonas prohibidas que ya contasen con licencia para el alquiler turístico, en ese caso podrán seguir practicándolo.

Salvo estas excepciones, el alquiler turístico queda restringido a las urbanizaciones turísticas en toda la isla, con solo cinco excepciones: Fornells, Sa Mesquida, Es Murtar, Es Grau y Cala Sant Esteve.

Esta situación no sufrirá cambios al menos durante los dos próximos años y no podrán concederse nuevas licencias de actividad hasta que no se lleve a cabo la revisión del Plan Territorial Insular (PTI). Solo si el PTI flexibiliza, en esa revisión, las restricciones al alquiler vacacional, la situación de cara a esta actividad podría cambiar en el futuro.

Los ayuntamientos pidieron en el trámite de alegaciones de principios de año, que el alquiler vacacional fuera permitido en las viviendas unifamiliares aisladas (chalés) ubicados en los núcleos urbanos, pero el Consejo no atendió su petición.

\subsection{Zonificación del alquiler turístico en Ibiza}

Siguiendo a Miguel Planas en Hosteltur sobre las estancias turísticas en viviendas de Ibiza, la modificación de la ley 8/2012, de 19 de julio operada a través de la Ley 6/2017 de 31 de julio, establece nuevas exigencias a las viviendas que comercializan estancias turísticas tanto a las nuevas, como a las ya inscritas, e incluso hace extensivo esta obligación a las viviendas turísticas de vacaciones.

De este modo, desde el 1 de agosto de 2018 se pueden presentar DRIATS (declaración Responsable del inicio de Actividad), para la inscripción de viviendas con el objeto de comercializarlas como tales, siempre que cumplan unos requisitos tipificados en el art. 50 de la Ley 8/2012. Planas, afirma: "Los ayuntamientos tenían que incluir en la documentación que enviasen al Consejo Insular de Ibiza los motivos considerados "de interés general" que justificasen las prohibiciones o restricciones que proponían. Independientemente de la decisión que adoptase cada uno de los consistorios", sin embargo, el Consejo de Ibiza ya adelantó su intención de no autorizar esta actividad en los edificios plurifamiliares.

El problema actual es que, a diferencia de lo ocurrido en la Isla de Mallorca, en Ibiza llevan meses intentando aprobar en los distintos Plenos municipales la zonificación de la isla para delimitar las zonas aptas para comercializar, pero sigue sin haber consenso o acuerdo político.

\section{REGULACIÓN EN MADRID}

En el caso específico de la Comunidad de Madrid se analizan en profundidad las principales referencias normativas aplicables tanto en el ámbito de la comunidad autónoma como en el del ayuntamiento. 
En el caso concreto del área de influencia del ayuntamiento madrileño se analizará más adelante el Plan Especial de Hospedaje, que consiste en un conjunto de ordenanzas municipales aplicable en los diferentes distritos atendiendo a su distribución geográfica en anillos.

\subsection{Normativa aplicable a la Comunidad de Madrid en materia de apartamentos y viviendas de uso turístico}

La normativa sobre las distintas tipologías de alojamiento en la Comunidad de Madrid está recogida en:

- Decreto 159/2003, de 10 de julio, de Ordenación de Establecimientos Hoteleros de la Comunidad de Madrid (modificado por el Decreto 77/2006, de 28 de septiembre, por el que se modifica la ordenación de establecimientos hoteleros de la Comunidad de Madrid); referido a las tipologías de: Hotel, Hotel-Apartamento, Pensión, Hostal, Casas de Huéspedes.

- Decreto 79/2014, de 10 de julio, del Consejo de Gobierno, por el que se regulan los apartamentos turísticos y las viviendas de uso turístico de la Comunidad de Madrid;referidoalastipologíasde:apartamentosturísticosyviviendasdeusoturístico.

En primer lugar, por lo que respecta a la regulación en el territorio de la comunidad de autónoma de Madrid se analiza el decreto 79/2014, por el que se regulan los apartamentos turísticos y las viviendas de uso turístico, como nueva modalidad de alojamiento. La Comunidad de Madrid tiene atribuida la competencia exclusiva en materia de promoción y ordenación del turismo en su ámbito territorial según lo dispuesto en el artículo 26.1.21 del Estatuto de Autonomía de la Comunidad de Madrid y además lo ampara el Real Decreto 697/1984, de 25 de enero, sobre traspaso de funciones y servicios del Estado a la Comunidad de Madrid en materia de turismo, que incluye en su Anexo I, apartado B), las funciones y servicios del Estado que asume la Comunidad Autónoma. Entre dichas funciones y servicios figura la ordenación de los establecimientos y empresas turísticas. Asimismo, la Ley 1/1999, de 12 de marzo, de Ordenación del Turismo de la Comunidad de Madrid, en su artículo 25, enumera las modalidades de alojamiento turístico, ofreciendo la posibilidad de incluir en dicha enumeración la regulación de "cualquier otra que reglamentariamente se determine".

Así el decreto 79/2014 pretende regular las denominadas viviendas de uso turístico, como nueva modalidad de alojamiento y reconoce textualmente en su preámbulo que su motivación consiste en "paliar los efectos de la inmersión en el ámbito turístico de una sobreoferta descontrolada de viviendas destinadas al uso turístico, se hace precisa su regulación con el fin de establecer unos mínimos requisitos tendentes a proteger los legítimos derechos de los usuarios y consumidores turísticos de la Comunidad de Madrid. A ello hay que añadir la necesidad de acabar con situaciones de intrusismo y competencia desleal constantemente denunciadas por las asociaciones del alojamiento madrileño y, en cualquier caso, poner freno a una oferta que podría estar ejerciendo una actividad opaca a las obligaciones fiscales que son exigibles al resto de los establecimientos turísticos".

\subsubsection{Disposiciones comunes a apartamentos turísticos y viviendas de uso turístico}

Se aportan las definiciones básicas para delimitar el objeto y el ámbito de aplicación del decreto: 
1. Definición de apartamento turístico: se consideran apartamentos turísticos los inmuebles integrados por unidades de alojamiento complejas, dotadas de instalaciones, equipamientos y servicios en condiciones de ocupación inmediata, destinados de forma habitual por sus propietarios o representantes, al alojamiento turístico ocasional, sin carácter de residencia permanente para los usuarios, mediante precio y cumplan con el principio de unidad de explotación.

2. Definición de vivienda de uso turístico: tienen la consideración de viviendas de uso turístico aquellos pisos, estudios, apartamentos o casas que, de forma habitual, amueblados y equipados en condiciones de uso inmediato, son comercializados y promocionados en canales de oferta turística o por cualquier otro modo de comercialización o promoción, para ser cedidos en su totalidad con fines de alojamiento turístico y a cambio de un precio.

3. Ejercicio habitual de la actividad turística: la actividad de alojamiento turístico se ejerce de forma habitual desde el momento en que el interesado se publicita por cualquier medio y presenta la preceptiva Declaración Responsable de inicio de actividad prevista en los artículos 11 y 17 del mencionado decreto 79/20.

4. Certificado de idoneidad para vivienda de uso turístico (CIVUT).

A los efectos de lo dispuesto en este Decreto se entiende por CIVUT el documento emitido por técnico competente en el que, tras efectuar una comprobación in situ, se acredita que una vivienda de uso turístico cumple los requisitos establecidos en el artículo 17 bis de este Decreto. Serán técnicos competentes para la suscripción de dicho CIVUT quienes están en posesión del título de arquitecto o arquitecto técnico.

La regulación de la prestación del servicio de alojamiento, el computo de las estancias, la normativa sectorial, remisión de documentación, derechos y deberes de los usuarios, así como la protección de seguridad ciudadana, el uso turístico y las dispensas de carácter general, vienen especificados.

\subsubsection{Requisitos mínimos correspondientes a cada categoría de apartamento}

El decreto nos informa sobre la composición de cada categoría de apartamento turístico:

- Han de estar ubicados en la totalidad de un edificio, o en parte independizada del mismo, con accesos y escaleras de uso exclusivo, debiendo cumplir los requisitos mínimos de clasificación contenidos en este decreto.

- Cada unidad de apartamento turístico estará compuesta, como mínimo, por un salóncomedor, cocina, dormitorio y baño, pudiendo denominarse "estudios" cuando el dormitorio esté integrado en una pieza común con el salón-comedor-cocina y cuente con un máximo de dos plazas en camas convertibles.

- Los inmuebles explotados como apartamentos turísticos se compondrán como mínimo de cuatro unidades de alojamiento.

- Sobre su identificación con llaves y clasificación, de una a cuatro, nos detalla el decreto los requisitos mínimos por categorías. Del mismo modo se regula la capacidad máxima de dos plazas por apartamento extensible a dos en camas convertibles siempre que sea posible por superficie y distribución, sin dar más detalle sobre las medidas de referencia para ampliar la capacidad en este sentido. 
- Existe obligatoriedad de mostrar en lugar visible en la recepción los precios tanto del alojamiento en si como de los servicios anexos.

- La oferta de habitaciones adaptadas, dispensas de superficie en habitaciones y cuartos de baño también se regula. En relación con la placa identificativa se exige en la entrada al establecimiento.

\subsubsection{Condiciones necesarias que deben reunir las viviendas de uso turístico para ejercer su actividad}

Se realiza especial hincapié en la obligación, forma y lugar de presentación de una declaración responsable de inicio de la actividad de alojamiento turístico, recayendo dicha responsabilidad sobre los propietarios o representantes. Se remite al régimen de la Ley 49/1960, de 21 de julio, sobre propiedad horizontal, cuando se trate de viviendas de uso turístico sometidas a dicha ley, en cuyo caso el destino de vivienda al uso turístico podrá limitarse o condicionarse en los términos establecidos en la referida ley. Matiza este decreto que si el número de viviendas de uso turístico implantadas en un edificio, portal o equivalente, unitario, es del $100 \%$ perteneciente al mismo propietario le será de aplicación la normativa para apartamentos turísticos, no pudiéndose alegar la condición de domicilio para impedir la acción de la inspección competente.

Poseen especial relevancia los artículos 17 (bis) 18 del referido decreto que establecen los requisitos que acredita el Certificado de idoneidad para vivienda de uso turístico (CIVUT) delimitando aspectos prácticos sobre dotación, distribución del espacio, seguros, hojas de reclamaciones y demás aspectos prácticos. Los precios y la placa distintiva habrán de mostrarse en la entrada y en la puerta respectivamente.

\subsubsection{Régimen sancionador}

El régimen sancionador aplicable a los apartamentos turísticos y a las viviendas de uso turístico se rige por lo dispuesto en el capítulo II, de la disciplina turística del Título IV del Control de la Calidad de la Ley 1/1999.

Acompañan a este decreto dos disposiciones transitorias y dos disposiciones finales que aclaran aspectos relativos al período transitorio y la entrada en vigor de la norma.

\subsection{Normativa aplicable al Ayuntamiento de Madrid en materia de apartamentos y viviendas de uso turístico}

En segundo lugar, en lo relativo a la normativa aplicable en área de influencia del ayuntamiento madrileño se analiza el Plan Especial de Hospedaje.

En marzo de 2019 el Ayuntamiento de Madrid acordó aprobar el Plan Especial de regulación del uso de servicios terciarios en la clase de hospedaje, distritos de Centro, Arganzuela, Retiro, Salamanca, Chamartín, Tetuán, Chamberí, Moncloa-Aravaca, Latina, Carabanchel y Usera, con las modificaciones introducidas en el documento tras el trámite de información pública, de conformidad con lo dispuesto en el artículo 59.2 de la Ley 
9/2001, de 17 de julio, del Suelo de la Comunidad de Madrid, en relación con los artículos 57 y 62.2 de la citada Ley.

De este modo el Plan Especial de Regulación del uso de Servicios Terciarios en la clase de Hospedaje (PEH), incorpora normas urbanísticas específicas y particulares para el ámbito de aplicación definido en ellas. Estas ordenanzas serán de aplicación con carácter preferente en dicho ámbito sobre la norma zonal u ordenanza particular del área de planeamiento correspondiente. Las Normas Urbanísticas (NNUU) del Plan General de Ordenación Urbana de Madrid (PGOUM 97) serán aplicables con carácter subsidiario para todas aquellas consideraciones no contempladas expresamente en las presentes Ordenanzas Particulares. En caso de existir contenidos contradictorios entre las determinaciones de las Normas Urbanísticas del Plan General de 1997 y las especificaciones de las presentes ordenanzas, prevalecerán las de estas últimas sobre las primeras.

El área de delimitación objeto del Plan Especial se halla recogida de forma gráfica en el plano que recoge la norma delimitando tres ámbitos, a modo de tres anillos concéntricos que detallan los barrios que los forman.

La norma establece las condiciones particulares en cuestión de uso terciario en clase de hospedaje en cada uno de los anillos, delimitando las situaciones autorizables, autorizables bajo un plan especial de protección y las no permitidas. Se dedica una buena parte del conjunto de ordenanzas al establecimiento de consideraciones medioambientales referentes cuestiones relacionadas con el aislamiento acústico, la limitación del consumo energético, la demanda energética y el rendimiento de las instalaciones térmicas e iluminación. Además, presta especial atención a la protección de la atmósfera, la protección de la calidad acústica, la protección de la calidad de los suelos, medidas sobre la gestión de residuos, la protección del paisaje y la escena urbana, la protección del patrimonio histórico y cultural, la protección de los recursos naturales.

\section{ANÁLISIS DE IMPACTO ECONÓMICO}

\subsection{Metodología de multiplicadores lineales}

Dado el carácter marcadamente transversal del fenómeno turístico, consideramos que una metodología pertinente para llevar el análisis perseguido en el presente estudio parte del conocido modelo input-output de Leontief, The Structure Of The World Economy, (1973) primeramente a nivel nacional como regional (análisis posterior sometido a la inminente publicación del Marco Input Output de la economía regional balear), siendo complementado con información sectorial específica proporcionada por fuentes estadísticas oficiales.

La metodología de multiplicadores de Leontief nos permite realizar el análisis empírico, trasladando los datos estadísticos recopilados por el INE, en la Tabla Input Output 2015, al campo práctico, realizando simulaciones de posibles escenarios, en lo que a demanda de alojamiento turístico se refiere, y sus efectos económicos, cuantificables, con datos actuales. Este planteamiento le otorga al presente trabajo la virtud de ofrecer una herramienta de simulación de cambios en la demanda agregada y de cuantificación de efectos de impacto sectorial. 
Simularemos mediante el modelo de multiplicadores una simulación en dos etapas: por un lado, introducimos el shock que supone una disminución de la demanda de alojamiento en hoteles y de consumo en restaurantes, para observar las variaciones que se producen en el resto de sectores de actividad. Por otro lado, introduciremos en el modelo un segundo shock, el aumento de la demanda en alojamientos "No de Mercado" y aumento del consumo "en supermercados" en lugar de restaurantes, como consecuencia de integración de los turistas en la vida cotidiana de las viviendas de uso turístico.

Empezaremos describiendo la relación del PIB con el turismo en la Tabla Input-Output de la economía española referida a2015. Para adaptarla a la modelización necesitamos analizar de forma más profunda el año de referencia y extraer datos las claves para la ejecución del estudio acorde a la realidad de contratación del alojamiento a través de plataformas digitales en viviendas de uso turístico. La aportación total que hizo en el año de referencia 2015 el sector turístico a la economía española se cifra en el 11\% del PIB.

Datos complementarios sobre características y niveles de gasto de los viajes turísticos se encuentran recogidos en el marco de las operaciones Egatur y Familitur. Desde 2015 estas encuestas han pasado a ser competencia del INE siendo realizadas hasta entonces por el Instituto de Estudios Turísticos, (IET), actualmente Subdirección General de Conocimiento y Estudios turísticos del Ministerio de Industria, Energía y Turismo. Tales encuestas recogen información crítica sobre el gasto de los turistas en los diferentes destinos españoles incorporando información sobre los que se alojan en viviendas de alquiler $\mathrm{y}$ en otros establecimientos.

En este sentido se expone en primer lugar una explotación de los datos presentados por Egatur, la Encuesta de Gasto Turístico, de 2016, 2017, 2018 y 2019 (último informe anual completo disponible a fecha de redacción de este trabajo) como aproximación al fenómeno que nos ocupa.

En 2019 el gasto medio por turista se sitúa en 1.155 euros, con un incremento anual del $3,6 \%$. Por su parte, el gasto medio diario crece un 4,3\%, hasta los 144 euros. Se observa una tendencia al alza en el gasto y más conservadora en cuanto al número de días.

Estos datos ilustran que España se consolida como destino turístico con una coyuntura internacional favorable hasta comienzos del 2020 y a partir de entonces se abre un horizonte de total incertidumbre como consecuencia de la sobrevenida epidemia del COVID-19.

Con el objetivo de cuantificar las externalidades generadas por la contratación del alojamiento turístico a través de plataforma digitales y sus efectos multiplicadores sobre el resto de la economía se han tomado datos de "Gasto de los turistas internacionales según tipo de alojamiento principal" procedentes de la encuesta EGATUR elaborada por el INE desde 2015.

El análisis empírico se basa en la metodología de multiplicadores lineales cuyos fundamentos teóricos repasaremos brevemente. Se realiza la simulación con datos reales del turismo español y su relación con el resto de la economía. El turismo es un mercado heterogéneo que no aparece como sector actividad en las cuentas nacionales, por tanto, comprende la actividad de diversas ramas económicas para hacer frente a la demanda de los turistas. Esto implica que la economía del turismo no tiene una rama de actividad específica y necesita de varios sectores para crear lo que conocemos como fenómeno turístico. Por ser un sector tan amplio, un cambio en cualquiera de sus variables crea 
un efecto arrastre en el conjunto del entramado productivo. Con la ayuda del Modelo de Multiplicadores Lineales podemos cuantificar tales efectos y el peso relativo de una industria o sector de actividad.

\section{Figura 2 \\ GASTO TOTAL DE LOS TURISTAS INTERNACIONALES SEGÚN TIPO DE ALOJAMIENTO PRINCIPAL}

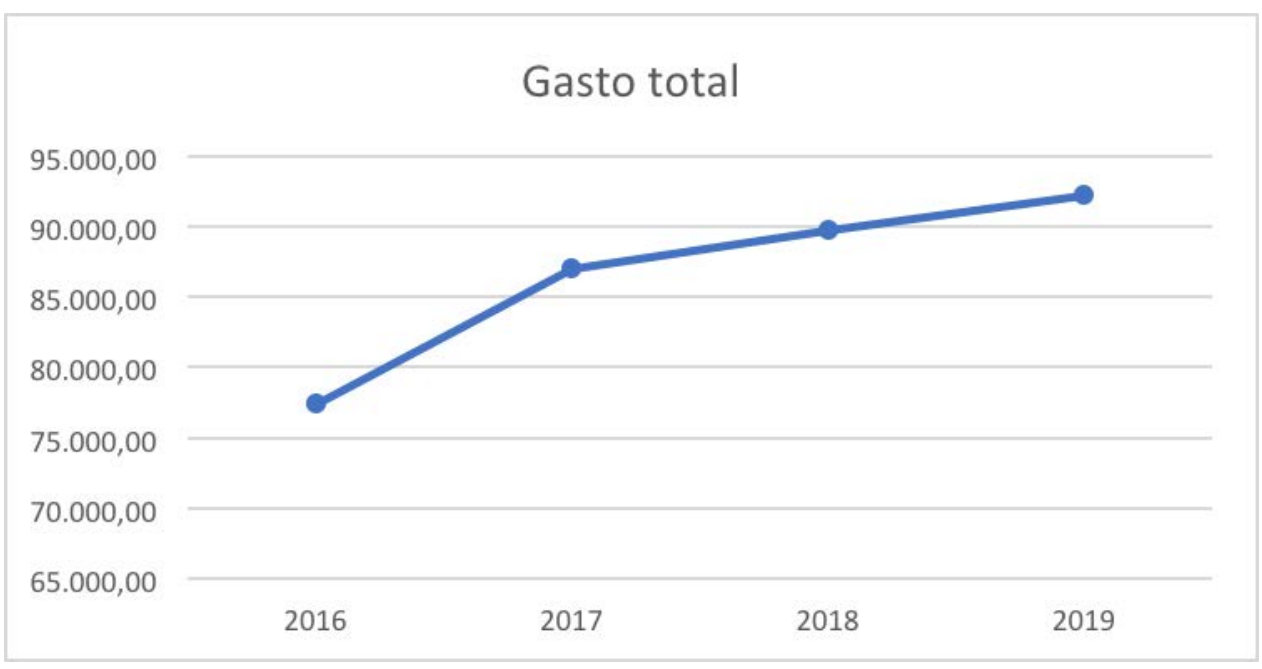

Fuente: Instituto Nacional de Estadística.

Por otro lado, se distinguen dos tipos de productos específicos:

- Productos característicos del turismo: son aquellos que en su ausencia dejaría de existir el turismo (las cuentas que utilizaremos para nuestro análisis).

- Productos conexos con el turismo: consumidos por los visitantes en cantidades que resultan importantes, aunque no figuran en la lista de productos característicos.

De la lista de productos característicos del turismo extraemos los siguientes:

a. Comercio y hostelería: Se compone de la suma del gasto en alojamiento y gasto en manutención. Si buscamos las partidas en la Tabla IO que aporta el INE, sus análogos son: la cuenta en Servicios de alojamiento y de comidas y bebidas.

b. Transporte y comunicación: Para los visitantes extranjeros si es cierto que esta partida se compone de servicio de transporte internacionales, pero para la demanda interna, según un Familitur, un $80 \%$ del turismo interno se desplaza por carretera.

c. Actividades. Financieras, inmobiliarias, profesionales y científicas: esta partida complementa el viaje, es decir, recoge la financiación del viaje, los alquiles de bienes, seguros de viajes, etc. 
d. Administración Pública, Sanidad, Educación y Actividades recreativas: en esta partida se refleja el motivo del viaje.

Todos estos datos, los recogemos en el siguiente cuadro con el peso real según la partida gastos.

Tabla 1

REGLA DE REPARTO EN PRODUCTOS CARACTERÍSTICOS DEL TURISMO

\begin{tabular}{|l|r|}
\hline 1. Hostelería & \multicolumn{2}{|c|}{$29,3 \%$} \\
\hline 2. Servicios inmobiliarios & $\begin{array}{l}\text { Imputaremos a esta rama la contratación de } \\
\text { viviendas de alquiler turístico a través de } \\
\text { plataformas digitales a efectos de simulación. }\end{array}$ \\
\hline 3. Transporte Viajeros & $21,2 \%$ \\
\hline 4. Alquiler de vehículos de transporte & $5,6 \%$ \\
\hline 5. Agencias de Viaje & $17,4 \%$ \\
\hline 6. Actividades Culturales & $20,9 \%$ \\
\hline 7. Actividades Deportivas y Recreativas & $5,6 \%$ \\
\hline
\end{tabular}

Fuente: Elaboración propia a partir de Egatur 2016

De esta forma, al aplicar las variaciones en la demanda final, hacemos un reparto aproximado a su peso relativo en la industria turística. Esto nos da paso a crear la simulación objeto de estudio a partir de los resultados publicados por el INE para el año 2015. Así, siendo la aportación del turismo a la economía española de 118.724,90 millones de euros en el año 2015, esto representó el 11\% del total del PIB. Se analizarán las externalidades y el cambio de modelo de contratación en el sector turístico aplicando la metodología de multiplicadores lineales de Leontief.

Profundizando en estos modelos los Multiplicadores Lineales estiman los efectos que producen cambios en las variables exógenas sobre las endógenas, es decir, nos permite un análisis que incluya los efectos directos, indirectos e inducidos. Nos da una visión más concreta de los mecanismos de interdependencias existente en la economía.

Para realizar dicho análisis primero hay que identificar qué cuentas serán las endógenas y cuáles serán las exógenas:

- Endógenas son aquellas cuentas que recoge el impacto de las cuentas exógenas, por lo general son aquellas que se encuentran fuera del sistema económico o son instrumento de políticas económicas.

- Exógenas son las cuentas que inducen el cambio sobre los valores de las cuentas endógenas.

La decisión de clasificación final dependerá de cuáles son los resultados que se quiera estudiar. Para este trabajo las cuentas endógenas de la Tabla Input-Output de España 2015 se compondrán de 47 ramas de actividad agregadas y aplicaremos el shock en la demanda final, a través de cambios en 4 cuentas exógenas: Servicios de alojamiento y de comidas y bebidas, Servicios de comercio al por menor, excepto de vehículos de motor y motoci- 
cletas, Servicios de alquiler y Servicios de agencias de viajes, operadores turísticos y otros servicios de reservas, y servicios relacionados con los mismos.

Los modelos de multiplicadores lineales son modelos lineales multisectoriales, en la cuales las cuentas endógenas se expresan como funciones lineales de las viables exógenas. Por lo tanto, la suma total de cualquier cuenta endógena se expresa como la suma de las transacciones de la cuenta endógena y las transacciones sobre las variables exógenas. Obtenemos la siguiente ecuación matricial:

$$
\mathrm{Y}=\mathrm{A} \cdot \mathrm{Y}+\mathrm{X}
$$

Dónde:

$\mathrm{X}$ : para una matriz de orden $\left(\mathrm{m}^{*} 1\right)$, (siendo $\mathrm{m}$ el número de cuentas endógenas) contiene la inyección de las cuentas exógenas.

Y: para una matriz de orden $\left(\mathrm{m}^{*} 1\right)$, formado por el ingreso total de las cuentas endógenas.

A: para una matriz de orden $\left(\mathrm{m}^{*} \mathrm{~m}\right)$, corresponde con el sector productivo, son los llamados coeficientes técnicos.

Despejamos:

$\mathrm{Y}=(\mathrm{I}-\mathrm{A})^{-1} \cdot \mathrm{X}$

Asumimos que $(\mathrm{I}-\mathrm{A})^{-1}=\mathrm{M}$ y da como resultado:

$\mathrm{Y}=\mathrm{M} \cdot \mathrm{X}$

$\mathrm{M}$ es la matriz de multiplicador lineal, donde cada ítem Mij muestra el cambio en el nivel de ingreso de la cuenta $i$, si la cuenta endógena $j$ recibe una unidad monetaria adicional de ingreso de la cuenta exógena. El vector resultante $\mathrm{Y}$ es la matriz que indica el grado en que una inyección exógena en el sistema afecta al ingreso total de las cuentas endógenas.

Mediante la matriz inversa de Leontief obtenemos el vector de multiplicadores, estos indican cómo una variación desde la cuenta exógena afecta al conjunto de cuentas endógenas.

Esta matriz permite conocer que cuentas de la economía del turismo generan mayores efectos de expansión en la economía española. Podremos identificar qué agentes tienen la capacidad de impulsar los niveles de renta de otros sectores. Son cuentas que poseen capacidad de arrastre, creando el efecto expansión hacia las otras cuentas.

\subsection{Análisis de impacto económico}

En 2018 el gasto medio por turista entre experimentó un crecimiento del 2,2\% respecto al año anterior, llegando a los 1.082 € según la estadística EGATUR. En 2019 siguió esta tendencia alcista alcanzando los $1.155 €$, representando esta cifra un incremento anual del $3,6 \%$. En lo que va de año 2020 el gasto total de los turistas internacionales que visitan España ha aumenta un 2,1\% respecto al mismo periodo de 2019.

Conociendo que el sector turístico es, directa o indirectamente responsable de la generación de más del 12,3\% del PIB de España y del 12,7\% del empleo total en 2018, según datos de la Cuenta Satélite del Turismo publicada por el INE, la simulación toma esta cifra y toma como punto de partida la base de datos Tabla Input-Output (TIO) 2015 agregada a partir del Marco Input-Output publicado por el INE para España. 
En primer lugar, se identifican las ramas de actividad vinculadas al fenómeno de estudio, se han identificado las siguientes son su peso relativo sobre el total de la economía tal y como se indica en la siguiente tabla, así mismo se han seleccionado las ramas de actividad que recibirán los impactos directos objeto de la simulación. Por un lado, los que reciben un primer impacto negativo son hoteles y restauración y en cambio los que reciben un segundo impacto positivo son servicios de comercio al por menor, servicios de alquiler y servicios relacionados con agencias, intermediarios y operadores turísticos.

Tabla 2

PESO RELATIVO DE CADA SECTOR DE ACTIVIDAD SOBRE EL TOTAL DE LA INDUSTRIA TURÍSTICA

\begin{tabular}{|c|l|c|}
\hline $\begin{array}{c}\text { CÓDIGO } \\
\text { SECTOR }\end{array}$ & \multicolumn{1}{|c|}{ SECTORES VINCULADOS AL TURISMO } & $\begin{array}{c}\text { PESO } \\
\text { RELATIVO }\end{array}$ \\
\hline \hline 22 & Comercio y hostelería & $0,35 \%$ \\
\hline 23 & Transporte y comunicaciones & $0,26 \%$ \\
\hline 24 & Actividades financieras, inmobiliarias, profesionales, científicas & $0,14 \%$ \\
\hline 25 & Adm. Pública, Sanidad, Educación, Act. Recreativas & $0,25 \%$ \\
\hline
\end{tabular}

Fuente: Elaboración propia.

Para resolver el problema matemático aplicamos la ecuación matricial que descompone la oferta y la demanda final en "consumos intermedios" y "demanda final", para pasar a despejar el output total, de la ecuación anterior y una vez calculada la Matriz de Multiplicadores del Modelo de Leontief "M" se aplica sobre la simulación planteada: primeramente, una reducción del 50\% del consumo hoteles y restauración y en servicios de alojamiento y de comidas y bebidas. En segundo lugar, se simula el aumento del 50\% en servicios de comercio al por menor, servicios de alquiler y servicios relacionados con agencias, intermediarios y operadores turísticos. Los resultados de resultados del primer impacto de la simulación descrita anteriormente quedan reflejados en la siguiente tabla:

Analizando las cifras resultantes de la simulación del primer impacto directo consistente en la reducción de la demanda en el sector Servicios de alojamiento y de comidas y bebidas, como consecuencia del cambio de hábitos de contratación del turista respecto, al consumo en hoteles y restauración, podemos resaltar como este hecho traído consigo los mayores efectos contractivos en los sectores que se detallan a continuación: Agricultura, ganadería silvicultura y pesca, Productos alimenticios; bebidas; tabaco manufacturado, Productos químicos, Energía eléctrica, gas, vapor y aire acondicionado, Construcciones y trabajos de construcción, Servicios de comercio al por mayor e intermediación del comercio, excepto de vehículos de motor, motocicletas y ciclomotores, Servicios de comercio al por menor, excepto de vehículos de motor y motocicletas, Servicios de transporte y auxiliares, Servicios financieros, seguros, reaseguros y planes de pensiones y auxiliares, Servicios inmobiliarios, Servicios de seguridad e investigación; servicios para edificios y paisajísticos y Servicios administrativos, de oficina y otros servicios de ayuda a las empresas. 


\section{Tabla 3 \\ RESULTADOS DEL PRIMER IMPACTO SIMULADO}

PRIMER PASO: REDUCCIÓN DEL 50\% DEL CONSUMO EN HOTELES Y RESTAURACIÓN

\begin{tabular}{|c|c|c|c|}
\hline \multirow[b]{2}{*}{$\begin{array}{l}\text { RAMAS DE ACTIVIDAD AGREGADAS DE LA TABLA } \\
\text { INPUT-OUTPUT ESPAÑA } 2015\end{array}$} & \multicolumn{3}{|c|}{ SIMULACIÓN } \\
\hline & $\begin{array}{c}\text { Total } \\
\text { demanda } \\
\text { final } X_{1} \\
\end{array}$ & $\begin{array}{c}\text { Nivel de } \\
\text { producción } \\
Y_{1} \\
\end{array}$ & DIFERENCIAS \\
\hline Agricultura, ganadería silvicultura y pesca & $26.347,9$ & $60.012,6$ & $-550,2$ \\
\hline Productos alimenticios; bebidas; tabaco manufacturado & 77.437 .9 & $156.710,3$ & $-2.528,8$ \\
\hline Productos textiles; prendas de vestir; artículos de cuero y calzado & $28.346,3$ & $42.382,7$ & $-84,1$ \\
\hline Madera, papel y servicios de impresión y reproducción & $7.003,7$ & $31.786,5$ & $-158,8$ \\
\hline Productos químicos & $24.476,6$ & $70.814,6$ & $-257,6$ \\
\hline Vehículos de motor, material de transporte & $84.268,1$ & $114.419,9$ & $-18,7$ \\
\hline Servicios de reparación e instalación de maquinaria y equipos & $6.458,3$ & $19.321,4$ & $-51,7$ \\
\hline Energía eléctrica, gas, vapor y aire acondicionado & $16.990,1$ & $80.448,4$ & $-327,1$ \\
\hline Agua, servicios asociados & $11.002,0$ & $27.850,9$ & $-86,1$ \\
\hline Construcciones y trabajos de construcción & $100.539,1$ & $145.699,8$ & $-157,5$ \\
\hline $\begin{array}{l}\text { Servicios de comercio al por mayor e intermediación del comercio, } \\
\text { excepto de vehículos de motor, motocicletas y ciclomotores }\end{array}$ & $60.262,1$ & $104.362,5$ & $-692,4$ \\
\hline $\begin{array}{l}\text { Servicios de comercio al por menor, excepto de vehículos de } \\
\text { motor y motocicletas }\end{array}$ & $49.647,7$ & $75.031,5$ & $-216,5$ \\
\hline Servicios de transporte y auxiliares & $38.889,7$ & $116.840,9$ & $-386,1$ \\
\hline Servicios de correos y mensajería & 336,2 & $4.726,6$ & $-34,8$ \\
\hline Servicios de alojamiento y de comidas y bebidas & $90.804,3$ & $103.554,3$ & $-9.933,0$ \\
\hline Servicios de edición y cinematográficos & $10.780,0$ & $19.109,5$ & $-44,6$ \\
\hline Servicios de telecomunicaciones & $14.401,8$ & $28.773,1$ & $-114,9$ \\
\hline $\begin{array}{l}\text { Servicios financieros, seguros, reaseguros y planes de pensiones y } \\
\text { auxiliares }\end{array}$ & $27.321,9$ & $71.748,5$ & $-267,5$ \\
\hline Servicios inmobiliarios & $106.520,4$ & $149.986,0$ & $-584,6$ \\
\hline Servicios juridicos, contables, técnicos, ingenieria, $\mathrm{i}+\mathrm{d}$ & $38.403,4$ & $87.495,3$ & $-235,1$ \\
\hline Servicios de publicidad y de estudio de mercado & $2.095,9$ & $16.645,4$ & $-88,1$ \\
\hline $\begin{array}{l}\text { Otros servicios profesionales, científicos y técnicos; servicios } \\
\text { veterinarios }\end{array}$ & 788,3 & $11.236,4$ & $-76,6$ \\
\hline Servicios de alquiler & $1.828,5$ & $15.718,4$ & $-69,4$ \\
\hline $\begin{array}{l}\text { Servicios de agencias de viajes, operadores turísticos y otros } \\
\text { servicios de reservas, y servicios relacionados con los mismos }\end{array}$ & $11.425,2$ & $12.358,1$ & $-2,1$ \\
\hline $\begin{array}{l}\text { Servicios de seguridad e investigación; servicios para edificios y } \\
\text { paisajísticos; servicios administrativos, de oficina y otros servicios } \\
\text { de ayuda a las empresas }\end{array}$ & $5.345,5$ & $47.602,3$ & $-233,4$ \\
\hline
\end{tabular}

Fuente: Elaboración propia.

Los resultados del segundo impacto directo consistente en aumentar la demanda en servicios de comercio al por menor, servicios de alquiler y servicios relacionados con agencias y operadores turísticos quedan reflejados en la siguiente tabla: 


\section{Tabla 4 \\ RESULTADOS DEL SEGUNDO IMPACTO SIMULADO}

SEGUNDO PASO: AUMENTO DEL 50\% EN SERVICIOS DE COMERCIO AL POR MENOR, SERVICIOS DE ALQUILER Y RELACIONADOS CON AGENCIAS Y OPERADORES TURÍSTICOS

\begin{tabular}{|c|c|c|c|}
\cline { 2 - 3 } \multicolumn{1}{c|}{} & \multicolumn{2}{c|}{ SIMULACIÓN } \\
\hline $\begin{array}{c}\text { RAMAS DE ACTIVIDAD AGREGADAS DE LA TABLA } \\
\text { INPUT-OUTPUT ESPAÑA } 2015\end{array}$ & $\begin{array}{c}\text { Total } \\
\text { demanda } \\
\text { final } \mathrm{X}_{2}\end{array}$ & $\begin{array}{c}\text { Nivel de } \\
\text { producció } \\
\mathrm{n} \mathrm{Y}_{2}\end{array}$ & DIFERENCIAS \\
\hline
\end{tabular}

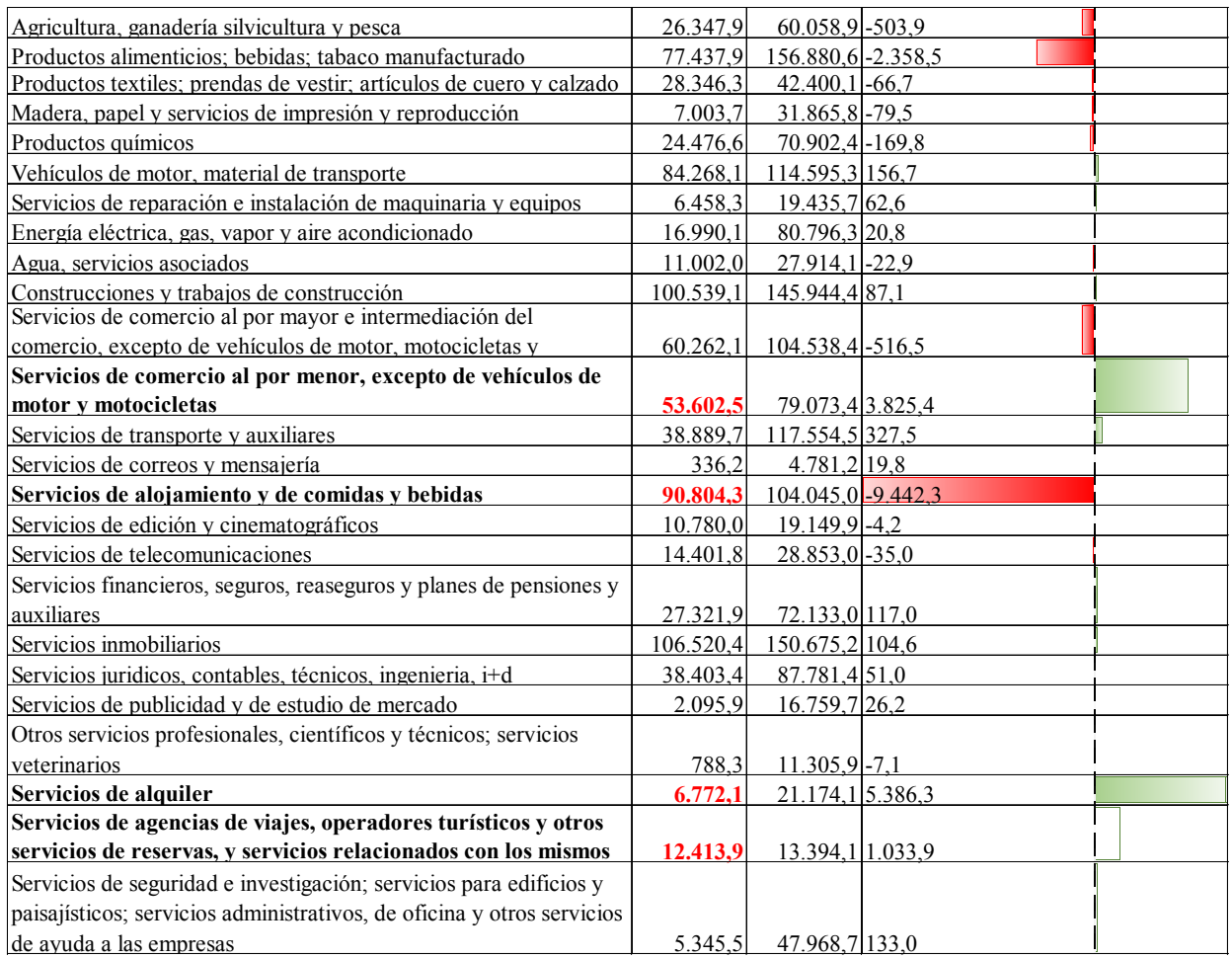

Fuente: Elaboración propia.

Analizando las cifras resultantes de la simulación podemos extraer la siguiente lectura:

Sectores en los que la caída originada por el primer impacto no se compensa con la subida por el segundo impacto.

1.Agricultura, ganadería, silvicultura y pesca

2.Productos alimenticios; bebidas; tabaco manufacturado

3.Productos textiles; prendas de vestir; artículos de cuero y calzado

4.Madera, papel y servicios de impresión y reproducción

5.Productos químicos 
Sectores en los que la caída debida al primer impacto si se compensa con la subida por el segundo impacto

6.Energía eléctrica, gas, vapor y aire acondicionado

7.Agua, servicios asociados (casi al completo)

8.Construcciones y trabajos de construcción

Sectores que sufren estímulo positivo debido a los efectos directos, indirectos e inducidos.

1.Construcciones y trabajos de construcción

2.Servicios de comercio al por mayor y al por menor y servicios de reparación de vehículos de motor y motocicletas

3. Servicios de transporte y auxiliares

4.Servicios financieros, seguros, reaseguros y planes de pensiones y auxiliares

5.Servicios inmobiliarios

6. Servicios jurídicos, contables, técnicos, ingeniería, I+D

7.Servicios de seguridad e investigación; servicios para edificios y paisajísticos; servicios administrativos, de oficina y otros servicios de ayuda a las empresas.

\section{CONCLUSIONES}

En este análisis se ha constatado la existencia de externalidades de diversa índole que han sido consecuencia del surgimiento de las viviendas de uso turístico y su contratación a través de las plataformas digitales. Ante esta circunstancia se pone de manifiesto la necesidad de conciliar los intereses de los diversos agentes implicados.

Se observa que la tecnología es un instrumento estratégico de competitividad turística y por tanto es decisión acertada seguir invirtiendo en alta tecnología, así como aplicar herramientas de gestión de grandes volúmenes de información, y profundizar en la aplicación de las herramientas para anticiparse, influir y proponer fórmulas que se adapten a los gustos y preferencias de sus huéspedes.

Se valora de forma positiva cómo la regulación a través de reales decretos, ordenanzas y mecanismos regulatorios se consigue ordenar una actividad, que los primeros años carecía de normativa específica y podría haber causado ciertas asimetrías entre los diferentes agentes que intervienen en la industria. Se ve que han aumentado los requerimientos legales sobre la solicitud de información por parte de las autoridades. Es deseable que exista convergencia regulatoria entre comunidades autónomas y en línea con destinos turísticos de otros lugares del mundo que nos preceden en experiencia y prácticas legislativas.

En este sentido, la actual regulación de ETV de las Islas Baleares es restrictiva en la mayor parte de la comunidad autónoma, principalmente en la capital. Hay que partir de la base que este tipo de viviendas surgen tras la crisis 2010-2016, porque supuso un buen momento para los propietarios, de amortiguar el efecto de la crisis económica, fomentando la economía sumergida. 
Ante esta situación, era necesario un control jurídico y fiscal con el fin de acabar con una realidad que creaba una competencia desleal en el sector hotelero, y paralelamente una saturación turística en algunos puntos de las islas. La normativa se reguló en Baleares al coincidir el auge de las visitas turísticas a España por conflictos geopolíticos en países como Egipto, Turquía, Grecia en el entorno del Mediterráneo.

En Madrid, el PEH de marzo de 2019, incorpora una serie de normas urbanísticas específicas y particulares, ordenanzas municipales, para el ámbito de aplicación definido en ellas.

Siguiendo la metodología de nuestro estudio pasamos a extraer unas breves reflexiones:

En clave económica las cifras indican que la industria turística española se consagra año tras año como motor económico y social, no carente de transformaciones. Tras cuantificar el impacto sobre los principales agregados macroeconómicos mediante el modelo lineal de Leontief, surge un debate en torno al cambio de comportamiento social y de perfil del turista. Se puede plantear si este nuevo turista desplaza al turista de hotel o se trata de un tipo de turista que de otro modo no viajaría. Las cifras resultantes del ejercicio de simulación muestran que, aun pudiendo entrar en conflicto las dos tipologías de turistas, el efecto económico agregado es positivo en términos macroeconómico, debido a las interrelaciones que existen entre los diferentes sectores que intervienen en la industria turística española. Efectos que se ejercen desde la doble óptica de los efectos arrastre y empuje de los sectores económicos. La magnitud de la situación impone entablar un diálogo con representantes de los agentes involucrados ya que la simulación realizada nos informa que los efectos negativos de la sustitución de la demanda hotelera por vivienda de uso turístico no se compensan con los efectos arrastre que sobre los sectores vinculados al introducir al turista como un vecino más.

En clave social sí cabría plantear un debate en torno a aspectos derivados de las nuevas fórmulas turísticas que pertenecen a la esfera de lo ético y lo estético.

En clave laboral todo el análisis pone de relieve lo dependiente que es el mercado laboral español de la actividad en el sector turístico. Es un sector que posee la ventaja de dar cabida a colectivos desde un baja-media cualificación hasta una alta cualificación. Siendo deseable alcanzar unos niveles de cualificación paulatinamente mayores que vayan asociados a salarios competitivos. No obstante, para alcanzar tales objetivos se deben impulsar cursos de capacitación del capital humano, instaurar códigos éticos de conducta laboral en las empresas que contrarresten la economía sumergida y las prácticas laborales irregulares, así como reforzar la obtención de certificaciones de calidad en las empresas del sector.

En clave patrimonial es necesario regular en cascos históricos y en costas con el fin de que no se degraden los valores históricos, lugares emblemáticos y la salubridad de las playas debido a la saturación turística.

En clave medioambiental una vez concienciados del problema derivado del cambio climático es importante alcanzar en el año 2030 la meta 8de las ODS, dónde se enuncia poner en práctica políticas encaminadas a promover un turismo sostenible.

En este trabajo se ha abordado este tema en el que el análisis se ha desarrollado desde diferentes ángulos para proporcionar una visión global, cuantificada y una reflexión final.

Las grandes cadenas hoteleras, como profesionales del alojamiento de calidad, han de saber interpretar y aprovechar las nuevas oportunidades de negocio sabiendo anticiparse a los movimientos sociales y digitales. En este sentido los modelos matemáticos de simulación de impacto económico poseen la virtud de cuantificar los efectos de cambios en cualquier 
componente de la demanda agregada, por ello si existe estabilidad en el entorno económico internacional los resultados pueden conducirnos a aproximaciones fiables sobre el efecto de tales variaciones. No obstante, en momentos convulsos como el de reciente actualidad, debido a cualquier efecto incontrolable a escala mundial, rompería cualquier cálculo inicial.

En el primer trimestre del año 2020 la Organización para la Cooperación y el Desarrollo Económico (OCDE) plantea un escenario optimista y aun así ha recortado drásticamente su previsión de crecimiento global de un 2,9\% hasta el 2,4\% y ve a Europa muy vulnerable ante una crisis prolongada. Bajo un escenario más pesimista, esto es, si la epidemia se prolonga en el tiempo y en la geografía, el crecimiento previsto para la economía global se reduciría a la mitad, hasta el 1,5\% y la Eurozona y Japón podrían entrar en recesión. Este panorama tensa la expectativa en todos los ámbitos, no sólo el que nos ocupaba en el turismo, foco del presente trabajo, sino de todos los demás de forma interconectada, tal y como hemos visto en la simulación descrita en el presente trabajo.

Suscribimos las palabras de Guillén Navarro (2015:144) que sostiene que "residir vacacionalmente de alquiler privado es una opción legítima, familiar y socialmente saludable, pero cuando se entra en el tablero turístico, los participantes deben acatar las reglas del juego impuestas para el resto. Nos encontramos ante una actividad turística que debe ser reglada ya no sólo por la problemática que genera (competencia desleal, economía sumergida, problemas vecinales, impacto urbanístico, gentrificación, desprotección del turista/consumidor, etc.), sino porque ante todo se pone en tela de juicio la calidad del destino España" (en Bermejo Latre, 2015).

A la fecha de cierre de este artículo se ha producido la pandemia de COVID-19, es por ello por lo que, se considera pertinente emitir una reflexión acerca del impacto sobrevenido en la industria turística. Se constata la permeabilidad del engranaje turístico español ante cualquier eventualidad, en un contexto internacional de economías globalizadas e interconectadas. En este caso concreto se trata de una crisis sin precedentes que ha supuesto una parálisis de todos los sectores que conforman la industria turística.

La situación es incierta, y como afirma Ángeles Rubio (2020) supone un problema de "extraordinaria relevancia" por ser el sector que más aporta a la economía española, cifrada en el 15\% del PIB, si sumamos efectos directos e indirectos, y debido también a los efectos multiplicadores del turismo sobre la producción interna y la renta. Asimismo, las consecuencias también han alertado a la Federación Española de Asociación de Viviendas de Uso Turístico y apartamentos (FEVITUR) que han propuesto un paquete de medidas urgentes para aplacar los efectos negativos de esta pandemia; entre las medidas sugeridas está la promoción de comunidades autónomas, para favorecer un turismo interno, el que será una de las soluciones más generalizadas. Otro ejemplo, de carácter internacional y a medio plazo es el que propone la patronal hotelera de Baleares donde se están coordinando con turoperadores alemanes para probar y testar una zona "piloto" de estancia turística en Playa de Palma, siempre dentro de la prudencia sanitaria y hasta que llegue la ansiada vacuna, porque afirman que la incidencia de Covid-19 en estas islas han sido de las más bajas de España. En general, se requieren acciones coordinadas que ayuden a mermar el enorme impacto negativo en este sector. Deducimos que mientras no se logre consensuar un conjunto de medidas, incluso a nivel europeo, que involucren diversos sectores, todos ellos interconectados, desde la identificación del medicamento 
o vacuna, que ayuden a minimizar los efectos sobre la salud de la pandemia, hasta la necesaria incorporación de medidas que transmitan seguridad y confianza al viajero, para viajar de nuevo con garantías sanitarias, no asistiremos a la ansiada recuperación gradual del sector.

En la actualidad, el Instituto para la Calidad Turística Española (ICTE), ha puesto en marcha un sello de certificado de Turismo (Safe tourism certified) para sectores turísticos que voluntariamente quieran acceder a ello, y que sigan las normas sanitarias de prevención de COVID-19. No se descarta contar en un futuro con pasaportes sanitarios, que faciliten la movilidad entre fronteras. Todo ello, se lograría con la coordinación de autoridades sanitarias y gubernamentales. Se prevé que esta situación de parálisis se extienda hasta finales 2020 cuyos efectos se prolongarán durante 2021, se desconoce cuándo se podrá retornar a los niveles de actividad de 2018 y principios del 2019. Los modelos de actividad serán objeto de revisión y previsiblemente se desarrollarán estrategias y planes desconocidos en estos momentos con el fin de reposicionar el destino España de nuevo en el tablero. En ello, estaría el esfuerzo de todos los agentes sociales incluidos el de los propios turistas.

\section{REFERENCIAS BIBLIOGRÁFICAS}

AGENDA 2030 DE DESARROLLO SOSTENIBLE. Disponible en: https://www.un.org/ sustainabledevelopment/es/development-agenda.

BANCO DE ESPAÑA (2014): La competitividad del Sector Turístico. Disponible en: https://www.bde.es/f/webbde/SES/Secciones/Publicaciones/InformesBoletinesRevistas/BoletinEconomico/04/Fich/be0409-art5.pdf.

BERMEJO LATRE, J.L. y ESCARTÍN ESCUDÉ, V. (2010): «El impacto de la reforma de servicios en el sector del turismo», en Moreu Carbonell, E.: El impacto de la directiva Bolkestein y la reforma de los servicios en el derecho administrativo, Zaragoza, Gobierno de Aragón, pp. 495-512.

BOSSHART, D. y FRICK, K. (2006): The future of leisure travel. Trendstudy. GottliebDuttweiler-Institut Zurich.

BOIB Ley 6/2017, no. 93, 31 de julio de 2017.Disponible en: http://www.caib.es/eboibfront $/ \mathrm{ca} / 2017 / 10691$

BOIB Ley 6/2018, no.93, 28 de julio de 2018. "Delimitación zonal definitiva" Fascículo 131 -Sec1- pp.26059-26078.Disponible en:http:/www.caib.es/eboibfront/pdf/ es/2018/93/1014043

CUADRO RESUMEN DE DRIAT: Procedimiento para la comercialización de vivienda turística de una ETV en las Islas Baleares. Disponible en:http://www.caib.es/pidip2front/jsp/es/ficha-convocatoria/strongel-govern-explica-coacutemo-presentar-unadriat-para-hacer-comercializacioacuten-turiacutestica-de-viviendasstrong\#

CUENTA SATÉLITE DEL TURISMO DE ESPAÑA. Base 2010. Serie contable 20102017. Disponible en: https://www.ine.es/dynt3/inebase/index.htm?type=pcaxis\&path=/ t35/p011/base_2010/serie/\&file=pcaxis

DE ESTEBAN CURIEL, J, SÁNCHEZ GARCÍA, V. y ANTONOVICA, A. (2013): Turismo cultural y gestión de los museos, Madrid, Dykinson. 
DE LA ENCARNACIÓN, A.M. (2016):” El alojamiento colaborativo: Viviendas de uso turístico y plataformas virtuales". Revista de Estudios de la Administración Local y Autonómica, pp. 30-55.

DEL BUSTO, E., CEBALLOS, M. y PÉREZ GUERRA, R. (2019): «Marco normativo de los apartamentos y viviendas de uso turístico en España. Especial mención a la Comunidad Autónoma de Madrid», Revista de Análisis Turístico, vol. 26 (1), pp. 62-92.

DOLNICAR, S. (2018): Peer-to-Peer accommodation networks, Goodfellow Publishers, Ltd.

EPA (2018):Disponible en:https://www.tourspain.es/eses/ConocimientoTuristico/PoblacionActiva/Nota\%20EmpleoTurismo\%20A\%C3\%B1o\%202018.pdf

EXCELTUR (2018): Estudio sobre el empleo en el sector turístico español. Abril 2018. Disponible en:https://www.exceltur.org/wp-content/uploads/2018/04/ESTUDIOEMPLEO-SECTOR-TURISTICO-EXCELTUR.pdf

FAMILITUR (2018): Estadística nacional sobre viajes, pernoctaciones, duración media y gasto. Instituto Nacional de Estadística, INE. Disponible en: http://www.ine.es/jaxiT3/ Datos.htm?t=12427

FRANCH FLUXA, J. (2019): «La regulación de las viviendas de uso turístico en Baleares tras la última reforma legislativa", en Las viviendas vacacionales: entre la economía colaborativa y la actividad mercantil. Madrid, Dykinson, pp. 145-170

GARCÍA SÁNCHEZ, A. (2014): 20 años de la actividad turística en España, Madrid, Síntesis.

GONZÁlEZ- VARAS, I. (2015): Patrimonio cultural, conceptos, debates y problemas. Madrid, Cátedra.

GÖSSLING, S. y PEETERS, P. (2015): “Assessing tourism's global environmental impact 1900-2050", Journal of Sustainable Tourism, vol. 23 (5), pp. 639-659.

GUILLÉN NAVARRO, N.. (2015): «Las viviendas de uso turístico y su incidencia en el panorama normativo español», Revista Aragonesa de Administración Pública, $\mathrm{n}^{\circ}$ 45-46, pp. 101-144.

HERRERO SUÁREZ, C. (2017): «Las viviendas de uso turístico: ¿el enemigo a abatir? Reflexiones sobre la normativa autonómica en materia de alojamiento turístico», Revista de Estudios Europeos, $\mathrm{n}^{\mathrm{o}} 70$ pp.147-158

INE Hoteles: encuesta de ocupación, índice de precios e indicadores de rentabilidad, recuperado en:https:/www.ine.es/dyngs/INEbase/es/operacion.htm?c=Estadistica_C $\&$ cid $=1254736177015 \&$ menu $=$ ultiDatos $\& i d p=1254735576863$

LEONTIEF, W. (1936): "Quantitative Input-Output relations in the economic system of the United States", Review of Economics and Statistics, vol. 18, pp. 105-125.

LEONTIEF, W. (1973): "Structure of the World Economy", en Les Prix Nobel 1973, Stockolholm: Nobel Foundation. Reeditado en American Economic Review vol. 64 (6), (diciembre 1974)

MIRALLES MARUGÁN, P. y VILLAR LAMA, A. (2016): «Las viviendas de uso turístico: un análisis del conflicto», International Journal of World of Tourism, vol. 3 (6), pp. 22-35.

OMT (2004): Gestión de la saturación turística en sitios de interés natural y cultural. Madrid. Organización Mundial del Turismo. 
ONDA CERO: "Los hoteleros ofrecen la Playa de Palma como destino piloto tras el COVID-19" Publicado el 29 de abril 2020. Disponible en https://www.ondacero. es/emisoras/baleares/mallorca/noticias/hoteleros-ofrecen-playa-palma-como-destinopiloto-covid19_202004295ea96111128a0a0001947c72.html

PANORAMA OMT DEL TURISMO INTERNACIONAL Edición 2018, UNWTO. Disponible en: https://www.e-unwto.org/doi/pdf/10.18111/9789284419890

PLANAS FONT, M. (2020): "El boom legislativo de la vivienda de alquiler turístico", Hosteltur, Publicado 09 de febrero 2020. Disponible en: https://www.hosteltur.com/ comunidad/003101_el-boom-legislativo-de-la-vivienda-de-alquiler-turistico.html

PLANAS FONT, M. (2020): "Estancias turísticas en viviendas de Ibiza", Hosteltur, Publicado el 27 de enero 2020. Disponible en: https://www.hosteltur.com/comunidad/003876_estancias-turisticas-en-vivienda-en-ibiza.html

QUEROL, M. (2010): Manual de Gestión del Patrimonio cultural. Madrid, Akal.

ROMÁN MÁRQUEZ, A. (2018): "El nuevo decreto andaluz sobre viviendas particulares de uso turístico. Análisis a la luz de la agenda europea para la economía colaborativa", Cuadernos de Turismo, $\mathrm{n}^{\circ} 41, \mathrm{pp}$. 591-613.

RUBIO GIL, A. (2020): "El turismo español tras el COVID-19. Verano 2020”, Hosteltur, Publicado el 22 de abril 2020. Disponible en https://www.hosteltur.com/comunidad/004050_el-sector-turismo-espanol-tras-el-covid-19.html

SCHNEIDERMAN, E.T. (2014): “Airbnb in the city, retrieved on July 31, 2017”. Disponible en: https://ag.ny.gov/pdfs/AIRBNB\%20REPORT.pdf.

VELASCO KARS, A. (2016): «La polémica de la vivienda de uso turística y su disposición», Revista del Sector Inmobiliario, n 159 , pp. 8-11.

ZAAR, M. H. y PONTES DA FONSECA, M.A. (2019): “Turismo y consumo del espacio urbano en Barcelona. Análisis de la relación residente-turista en el barrio de La Barceloneta", Cuadernos de Turismo, n 44, pp. 487-514. 